\title{
Firing and intrinsic properties of antennal lobe neurons in the Noctuid moth Agrotis ipsilon
}

\author{
Céline Lavialle-Defaix ${ }^{\mathrm{a}}$, Vincent Jacob ${ }^{\mathrm{a}}$, Christelle Monsempès ${ }^{\mathrm{a}}$, Sylvia Anton ${ }^{\mathrm{b}}$, \\ Jean-Pierre Rospars ${ }^{\mathrm{a}}$, Dominique Martinez ${ }^{\mathrm{c}}$, Philippe Lucas ${ }^{\mathrm{a}, *}$ \\ ${ }^{a}$ UMR 1392 Institute of Ecology and Environmental Sciences of Paris (iEES-Paris), INRA, Route de Saint-Cyr, F-78026 Versailles cedex, France \\ b Neuroéthologie-RCIM, INRA-Université d'Angers, UPRES EA 2647 USC INRA 1330, 42 rue Georges Morel, 49071 Beaucouzé, France \\ ' UMR7503, Laboratoire Lorrain de Recherche en Informatique et ses Applications (LORIA), Centre National de la Recherche Scientifique (CNRS), Vandœuvre- \\ lès-Nancy, France
}

\section{A R T I C L E I N F O}

\section{Article history:}

Received 12 March 2015

Received in revised form 4 June 2015

Accepted 24 June 2015

Available online 27 June 2015

\section{Keywords:}

Antennal lobe

Olfaction

Local interneuron

Firing

Depolarizing afterpotential

\begin{abstract}
A B S T R A C T
The antennal lobe (AL) of the Noctuid moth Agrotis ipsilon has emerged as an excellent model for studying olfactory processing and its plasticity in the central nervous system. Odor-evoked responses of AL neurons and input-to-output transformations involved in pheromone processing are well characterized in this species. However, the intrinsic electrical properties responsible of the firing of AL neurons are poorly known. To this end, patch-clamp recordings in current- and voltage-clamp mode from neurons located in the two main clusters of cell bodies in the ALs were combined with intracellular staining on $A$. ipsilon males. Staining indicated that the lateral cluster (LC) is composed of $85 \%$ of local neurons (LNs) and $15 \%$ of projection neurons (PNs). The medial cluster (MC) contains only PNs. Action potentials were readily recorded from the soma in LNs and PNs located in the LC but not from PNs in the MC where recordings showed small or no action potentials. In the LC, the spontaneous activity of about $20 \%$ of the LNs presented irregular bursts while being more regular in PNs. We also identified a small population of LNs lacking voltage-gated $\mathrm{Na}^{+}$currents and generating spikelets. We focused on the firing properties of LNs since in about $60 \%$ of LNs, but not in PNs, action potentials were followed by depolarizing afterpotentials (DAPs). These DAPs could generate a second action potential, so that the activity was composed of action potential doublets. DAPs depended on voltage, $\mathrm{Ca}^{2+}$-channels and possibly on $\mathrm{Ca}^{2}$ ${ }^{+}$-activated non-specific cationic channels. During steady state current injection, DAPs occurred after each action potential and did not require high-frequency firing. The amplitude of DAPs increased when the interspike interval was small, typically within bursts, likely arising from a $\mathrm{Ca}^{2+}$ build up. DAPs were more often found in bursting than in non-bursting LNs but do not support bursting activity. DAPs and spike doublets also occurred during odor-evoked activity suggesting that they can mediate olfactory integration in the AL.
\end{abstract}

(c) 2015 Elsevier Ireland Ltd. All rights reserved.

\section{Introduction}

The insect antennal lobe $(\mathrm{AL})$ is the primary structure involved in processing olfactory information within the brain. Similar to the olfactory bulb of vertebrates, the AL is organized in glomeruli forming discrete neuropil compartments (Rospars, 1988).

Abbreviations: AL, antennal lobe; ALT, antennal lobe tract; CAN, calciumactivated non-specific cation; DAP, depolarizing afterpotential; HAP, hyperpolarizing afterpotential; $I_{\mathrm{Ca}}, \mathrm{Ca}^{2+}$ current; ISI, interspike interval; LC, lateral cluster; $\mathrm{LN}$, local neuron; MC, medial cluster; ORN, olfactory receptor neuron; PN, projection neuron.

* Corresponding author. Fax: +3313083 3119

E-mail address: philippe.lucas@versailles.inra.fr (P. Lucas).
Olfactory receptor neurons (ORNs) expressing a given odorant receptor, and thus having the same response profile, project their axons to the same glomerulus (Vosshall et al., 2000). This glomerular organization creates parallel information-processing channels. Within glomeruli three different types of neurons establish synaptic contacts. ORNs transduce the properties of olfactory stimuli into trains of action potentials and deliver this sensory input to the AL network. Local neurons (LNs) are intrinsic to ALs and connect the different glomeruli. Projection neurons (PNs) deliver the processed olfactory information to higher brain centers. In the periphery of the AL, cell bodies of PNs and LNs form two main clusters situated laterally (LC) and medially (MC). In moths, the macroglomerular complex is a sexually dimorphic 
structure specifically devoted to the processing of sex pheromone (Hansson and Anton, 2000).

LNs are highly diverse, both in their morphology and in their physiology. Indeed, LNs show a large diversity of glomerular innervation patterns, dendritic structures, densities and distribution of presynaptic terminals (Christensen et al., 1993; Fonta et al., 1993; Chou et al., 2010; Reisenman et al., 2011). While most LNs are GABAergic and thus inhibitory (Schafer and Bicker, 1986; Seki and Kanzaki, 2008; Wilson and Laurent, 2005), some LNs release other transmitters including neuropeptides (Carlsson et al., 2010), biogenic amines (Homberg and Müller, 1999) and others are cholinergic and thus excitatory (Chou et al., 2010; Fusca et al., 2013; Olsen et al., 2007; Shang et al., 2007). LNs also vary widely in their physiological properties, including their ion channels and their ability to generate action potentials (Husch et al., 2009a; Seki et al., 2010), odor response profile, temporal dynamics and spontaneous firing rate (Chou et al., 2010). These distinctive morphological and electrophysiological properties indicate that LNs play diverse roles in olfactory processing in the AL. Most PNs have their dendrites restricted to one single glomerulus, but PNs with multiglomerular arborizations have been found in moths, flies, and bees (Hansson and Anton, 2000). PN axons project to the lateral horn and the mushroom bodies via several antennal lobe tracts (ALT). PNs are usually cholinergic (Bicker, 1999; Homberg et al., 1995) and thus excitatory but GABAergic PNs were reported from the fruitfly and the honeybee (Schafer and Bicker, 1986).

Sensory inputs from a large number of ORNs converge onto a small number of PNs and are processed by the AL network resulting in a important transformation of odor representations between ORNs and PNs. Compared to their presynaptic ORNs, PNs are generally more sensitive and show less variability in trial-to-trial responses to a given odor, they are more broadly tuned to odors and their responses are more transient (Wilson, 2013). LNs create a dense network between all glomeruli of the AL. They establish synaptic contacts with ORN axon terminals (Ignell et al., 2009; Olsen and Wilson, 2008; Root et al., 2008) and have reciprocal synaptic connections with PN dendrites and other LNs (Huang et al., 2010; Warren and Kloppenburg, 2014; Wilson and Laurent, 2005; Yaksi and Wilson, 2010) and thus contribute actively to shaping and modulating PN responses.

The properties and the plasticity of olfactory responses have been well characterized in the moth Agrotis ipsilon both at the peripheral and central level using single sensillum and intracellular recordings, respectively. These methods have been used to quantify and model (Belmabrouk et al., 2011; Gremiaux et al., 2012; Jarriault et al., 2010; Martinez et al., 2013; Rospars et al., 2014) the ORN-to-PN transformations taking place in an identified glomerulus, the cumulus, processing the main component of the sex pheromone of this moth. However, an understanding of the intrinsic electrical properties of AL neurons is lacking in this and other moth species, and to our knowledge is only available to some extent in Manduca sexta (Kloppenburg et al., 1999; Mercer et al., 1995, 1996, 2005; Mercer and Hildebrand, 2002; Warren and Kloppenburg, 2014). Such understanding would be particularly useful since the AL of moths has emerged as an excellent model for studying olfactory processing in the central nervous system and its plasticity (Barrozo et al., 2011; Chaffiol et al., 2012; Deisig et al., 2012). With the aim of better understanding the mechanisms of olfactory processing within ALs, we developed an in situ patchclamp approach on sexually mature A. ipsilon male moths. We combined current- and voltage-clamp recordings from neurons located in the two main clusters of cell bodies in the ALs with intracellular staining. We specifically focused on the firing properties of LNs since we frequently observed that action potentials in these neurons were either followed by depolarizing afterpotentials (DAPs) or fired in doublets. We analyzed the mechanism involved in their generation and propose a putative role for DAPs and spike doublets in olfactory coding.

\section{Methods}

\subsection{Insects}

Experiments were performed with the moth $A$. ipsilon (Hufnagel 1766) (Lepidoptera: Noctuidae). The larvae were reared on an artificial diet (Poitout and Buès, 1974) and kept in individual plastic boxes at $23 \pm 1{ }^{\circ} \mathrm{C}$ and $50 \pm 5 \%$ relative humidity until pupation. Pupae were sexed and males and females were kept in separate rooms under a reversed $16 \mathrm{~h}: 8 \mathrm{~h}$ light:dark photoperiod at $23^{\circ} \mathrm{C}$. Newly emerged adults were separated daily and were provided with a $20 \%$ sucrose solution ad libitum. The day of emergence was considered as day 0 . Experiments were performed during the scotophase on virgin 5-day-old (sexually mature) males.

\subsection{Electrophysiological recordings}

Moths were anesthetized by $\mathrm{CO}_{2}$ and immobilized in a $1 \mathrm{ml}$ pipette tip. The scales were removed from the head. The head capsule was opened, by cutting a window between the two compound eyes and the bases of the antennae. The brain with antennal nerves and antennae attached was removed from the head capsule and pinned in a recording chamber. To facilitate access to the recording site, the brain was enzyme treated $(2 \mathrm{mg} / \mathrm{ml}$ papain and $4 \mathrm{mg} / \mathrm{ml} \mathrm{L}$-cysteine dissolved in extracellular saline solution) for $2-3 \mathrm{~min}$ at room temperature before the AL was desheathed using fine forceps.

Whole-cell patch-clamp recordings were achieved either in the current-clamp or in the voltage-clamp mode from the cell body of AL neurons located either in the lateral or the medial cluster. Neurons were not synaptically isolated but the antennal nerve was cut to block the sensory input from ORNs when working on neurons from the LC but not from the MC since access to the MC required to isolate the $\mathrm{AL}$ which was only maintained by the antennal nerve. The somata of the AL neurons were visualized with a fixed-stage upright microscope (BX51WI, Olympus) using a water-immersion objective ( $\times 40$ LUM Plan FL N). Electrodes were pulled from borosilicate glass capillary tubes (GC 150-10, Harvard Apparatus, Edenbridge, UK) and had a resistance between 6 and 8 MW when filled with the intracellular solution. For current clamp recordings, the pipettes were filled with an intracellular saline solution containing (in $\mathrm{mM}$ ): $150 \mathrm{~K}$ gluconate, $10 \mathrm{NaCl}, 1 \mathrm{CaCl}_{2}, 2$ $\mathrm{MgCl}_{2}, 10$ EGTA and 10 HEPES adjusted to $\mathrm{pH} 7.2$ (with $\mathrm{KOH}$ ), resulting in an osmolarity of $\sim 340 \mathrm{mOsm} / \mathrm{l}$. During experiments, if not stated otherwise, the AL were bathed constantly with extracellular saline solution containing (in $\mathrm{mM}$ ): $150 \mathrm{NaCl}, 4$ $\mathrm{KCl}, 6 \mathrm{CaCl}_{2}, 2 \mathrm{MgCl}_{2}, 10$ HEPES and 5 glucose adjusted to $\mathrm{pH} 7.2$ (with $\mathrm{NaOH}$ ) and to $360 \mathrm{mOsm} / \mathrm{l}$ (with mannitol). To record $\mathrm{Ca}^{2+}$ currents $\left(I_{\mathrm{Ca}}\right)$ in voltage-clamp recordings, $\mathrm{Na}^{+}$and $\mathrm{K}^{+}$currents were suppressed by ion substitution and pharmacological reagents. Pipettes were filled with a solution containing (in $\mathrm{mM}$ ): Cs-aspartate $150, \mathrm{NaCl} 10, \mathrm{CaCl}_{2} 1, \mathrm{MgCl}_{2}$ 2, EGTA 10, Mg-ATP 3 , Hepes 10 adjusted to $\mathrm{pH} 7.2$ (with $\mathrm{CsOH}$ ) and an osmolarity of $\sim 390 \mathrm{mOsm} / \mathrm{l}$. Neurons were superfused with saline containing $10^{-7} \mathrm{M}$ tetrodotoxin (TTX), $5 \mathrm{mM}$ 4-aminopyridine (4-AP) and $30 \mathrm{mM}$ tetraethylammonium- $\mathrm{Cl}$ (TEA-Cl). The membrane potential was clamped at $-80 \mathrm{mV}$. Current-voltage $(I-V)$ relationships of the peak $I_{\mathrm{Ca}}$ were generated from step protocols. Chemicals used to prepare saline solutions, including TEA-Cl (113042), 4-AP (A7,8403), flufenamic acid (FFA; F-9005) and $\mathrm{CdCl}_{2}$ (C-3141) were purchased from Sigma-Aldrich. TTX was purchased from Alomone (T-550). An $\mathrm{Ag}-\mathrm{AgCl}$ reference electrode was connected to the bath 
through an agar bridge filled with recording electrode solution. Recordings were made using an Axopatch 200B amplifier (Molecular Devices, Union City, CA, USA) controlled by pCLAMP10 (Molecular Devices). Electrophysiological data were filtered at $5 \mathrm{kHz}$ using a four-pole low-pass Bessel filter and sampled at $50 \mathrm{kHz}$ by a 16-bit A/D converter (Digidata 1440A, Molecular Devices). After the formation of a gigaohm seal ( $>5 \mathrm{GW})$, series resistances were measured (typically between 15 and $20 \mathrm{MW}$ and always below $30 \mathrm{MW}$ ). Subtraction of residual leakage currents was performed with an on-line $\mathrm{P} / 6$ protocol. Patch-clamp experiments were conducted at room temperature $\left(20-24^{\circ} \mathrm{C}\right)$.

For extracellular recordings ALs were visualized with a stereomicroscope (MZ16, Leica, Nanterre, France). Electrodes pulled from borosilicate glass capillary tubes (GC 150-10) were cut under a microscope (Leica DMIL, $\times 400$ total magnification) to a tip of $2 \mathrm{~mm}$ and filled with the extracellular saline solution used for patch-clamp recording. The same saline solution was used for perfusing the brain. Recordings were done using a CyberAmp 320 (Molecular Devices) controlled by pCLAMP10 (Molecular Devices). The biological signal was amplified $(\times 2000)$, high-pass $(1 \mathrm{~Hz})$ and low-pass $(3 \mathrm{kHz}$ ) filtered and sampled at $10 \mathrm{kHz}$ via a Digidata 1440 A acquisition board (Molecular Devices). A humidified and charcoal-filtered airflow $(70 \mathrm{l} / \mathrm{h})$ was continuously directed to the preparation through a $20 \mathrm{~cm}$ long glass tube ( $7 \mathrm{~mm}$ of diameter). Pheromone stimuli consisted of blowing an air puff $(5 \mathrm{l} / \mathrm{h})$ through a Pasteur pipette containing a filter paper loaded with $0.1 \mathrm{ng}$ of $(\mathrm{Z})$ 7-dodecenyl acetate (Z7-12:Ac; Pherobank, Wijk bij Duurstede, The Netherlands), the main pheromone component of $A$. ipsilon. The tip of the Pasteur pipette was introduced through a lateral hole within the tube carrying the permanent humidified air flow onto the antennae at $15 \mathrm{~cm}$ from its outlet.

Data are expressed as means \pm sem. Differences between means were tested for statistical significance by Student's $t$-test. For data analysis, Clampfit 10 (Molecular Devices), Spike2 (Cambridge Electronic Design Ltd., Cambridge, UK), Matlab (MathWorks, Natick, MA USA) and Prism 5 (GraphPad software, San Diego, CA, USA) software were used.

\subsection{Labeling and microscopy}

To label single cells after patch-clamp recordings, $1 \%$ neurobiotin (Vector laboratories, Burlingame, CA, USA) was added to the pipette solution. After the recordings, the brain was removed and immersed in $4 \%$ paraformaldehyde overnight at $4{ }^{\circ} \mathrm{C}$ and rinsed $5 \times 30$ min in Millonig's phosphate buffer $\left(2.3 \% \mathrm{NaH}_{2} \mathrm{PO}_{4} \cdot \mathrm{H}_{2} \mathrm{O}, 2.5 \%\right.$ $\mathrm{NaOH}$ and $2.6 \mathrm{~g}$ sucrose, $\mathrm{pH} 7.2$ ). The brain was dehydrated and rehydrated in ethanol series to make membranes more permeable and then incubated in phosphate buffer containing Alexa Fluor 488-conjugated streptavidin (diluted at 1/40, Invitrogen, St. Aubin, France), $1 \%$ bovine serum albumin and $0.2 \%$ Triton X-100 overnight
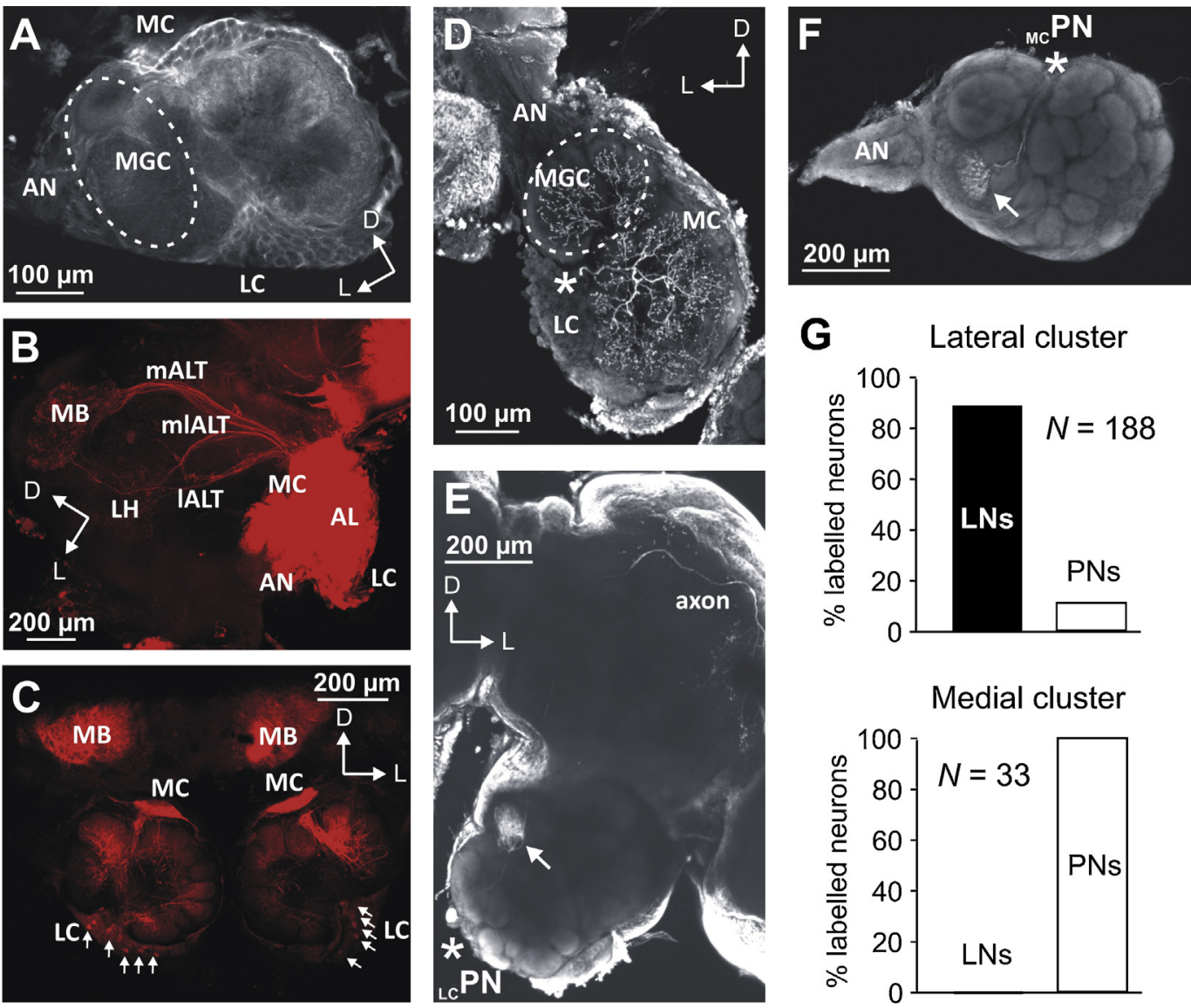

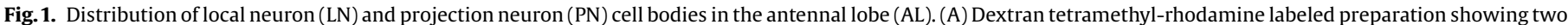

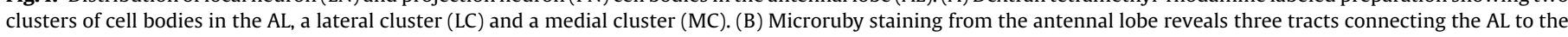

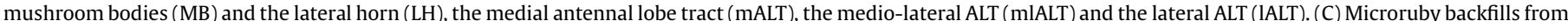

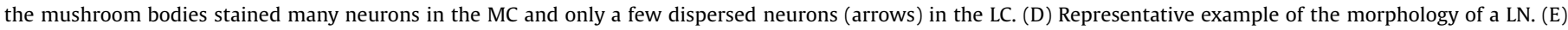

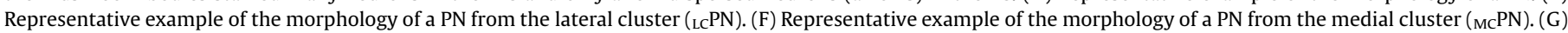

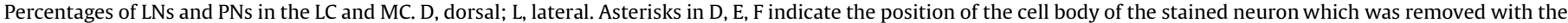

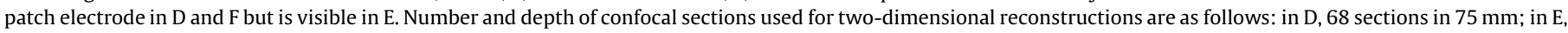
136 sections in $270 \mathrm{~mm}$; in F, 55 sections in $55 \mathrm{~mm}$. 
at $4{ }^{\circ} \mathrm{C}$. The brain was rinsed in phosphate buffer $(3 \times 10 \mathrm{~min}$ at room temperature) and then mounted on glass-slides in vectashield mounting medium (Vector laboratories, Burlingame, CA, USA). The fluorescence images were captured with a confocal scanning microscope (DMIRE2, Leica, Heidelberg, Germany) equipped with an HC PL APO CS $10 \times 0.4$ DRY objective. Streptavidin Alexa 488 was detected with the argon laser (excitation wavelength $488 \mathrm{~nm}$, detection range 500-650 nm). Images were recorded with Leica confocal software (version 2.61, Leica Microsystems Heidelberg GmbH, Germany) and processed with the software Image (version 1.47, National Institutes of Health, MD, USA).

For mass staining from the mushroom bodies and from the AL, access to the brain was prepared as in patch-clamp experiments. The mushroom body region or the center of the AL was then punctured with a fine glass electrode. A few crystals of Microruby (tetramethyl-rhodamine dextran with biotin, $3000 \mathrm{MW}$, lysinefixable, D-7162; Molecular Probes, Eugene, Oregon, USA) were gently applied to the punctured area by means of a broken micropipette. The brain was subsequently covered with a drop of extracellular saline solution and kept for $3 \mathrm{~h}$ in a moist dark chamber at room temperature to let the dye diffuse. Then, the brain was dissected, fixed and dehydrated as for single neuron labeling and it was cleared and mounted in methylsalicylate (M2047, Sigma-Aldrich). Brain preparations were observed with a confocal microscope (Leica TCS SP2; Leica Microsystems, Wetzlar, Germany) equipped with a diode laser. The excitation wavelength for rhodamine dextrane was $568 \mathrm{~nm}$ and the detection range 600$700 \mathrm{~nm}$.

\section{Results}

\subsection{Distribution of AL neuron cell bodies}

Two clusters of cell bodies were observed in each AL, a large lateral cluster (LC) and a small medial cluster (MC) as shown in dextran tetramethyl-rhodamine labeled preparations (Fig. 1A). The Microruby staining from the AL shows three tracts that connect the AL to the mushroom bodies and the lateral horn; the medial antennal lobe tract (mALT) projects first to the mushroom bodies
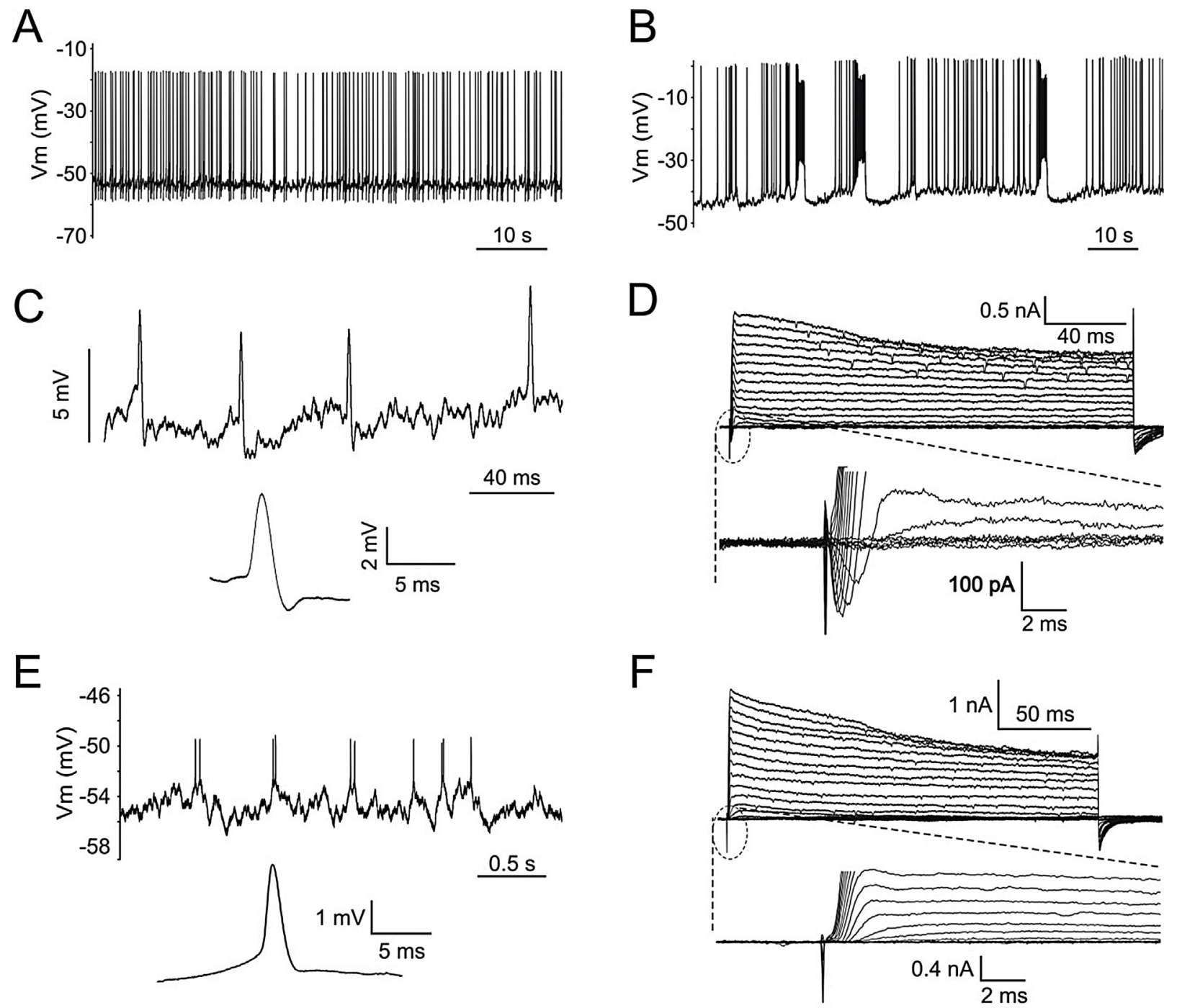

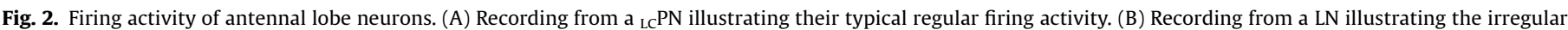

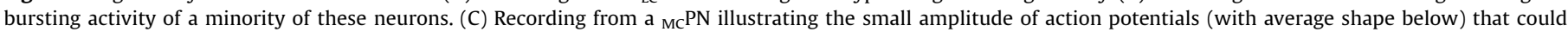

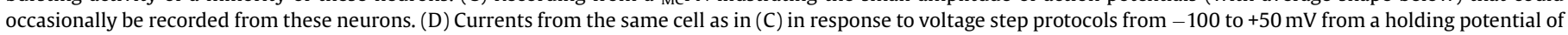

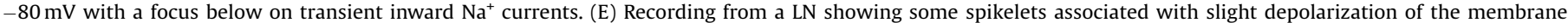

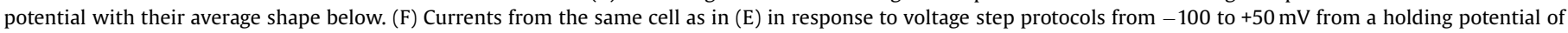
$-80 \mathrm{mV}$. No voltage-gated $\mathrm{Na}^{+}$current was activated. Transient downward peak is a capacitive artifact. 
and then to the lateral horn, the medio-lateral ALT (mlALT) projects only to the lateral horn, and the lateral ALT (IALT) projects first to the lateral horn and then to the mushroom bodies (Fig. 1B).

Microruby backfills from the mushroom bodies heavily stained the MC while staining just a few randomly distributed cell bodies in the LC. This staining pattern suggests that most PNs have their soma in the MC and only a few in the LC (Fig. 1C). This conclusion was confirmed by single neuron stains done after patch-clamp recordings. Indeed, a large majority of neurons stained in the LC (88\%, N=188) presented a typical morphology of LNs, with multiglomerular dendritic arborization and no axon (Fig. 1D). These LNs have a whole cell capacitance of $8.3 \pm 0.2 \mathrm{pF}(N=102)$.
The remaining neurons stained from the LC were PNs ( ${ }_{\mathrm{LC}} \mathrm{PNs}$ ), with an arborization in a single glomerulus and an axon projecting via the mALT to the MB (Fig. 1E). The capacitance of ${ }_{\mathrm{LC}} \mathrm{PNS}$ is $14.5 \pm 1.5 \mathrm{pF}(N=16)$. By contrast, all neurons labeled in the MC $(N=33)$ showed morphological characteristics of PNs ( $\left.{ }_{\mathrm{MC}} \mathrm{PNs}\right)$, they arborize in a single glomerulus and have an axon leaving the $\mathrm{AL}$ (Fig. 1F). However, the protocerebral projection of their axons could not be observed because removing the rest of the brain is required to record from that side of the AL. The capacitance of

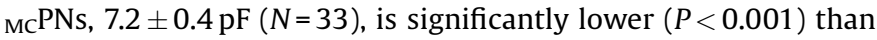
that of ${ }_{\mathrm{LC}} \mathrm{PNs}$. The capacitance of LNs is higher than that of ${ }_{\mathrm{MC}} \mathrm{PNs}$ $(P<0.05)$ but lower than that of ${ }_{\mathrm{LC}} \mathrm{PNs}(P<0.001)$.

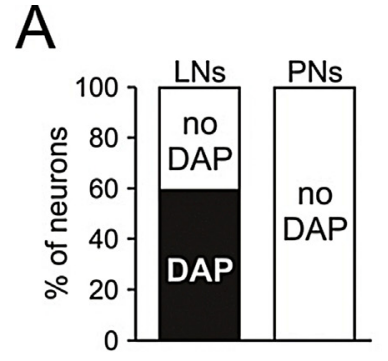

B

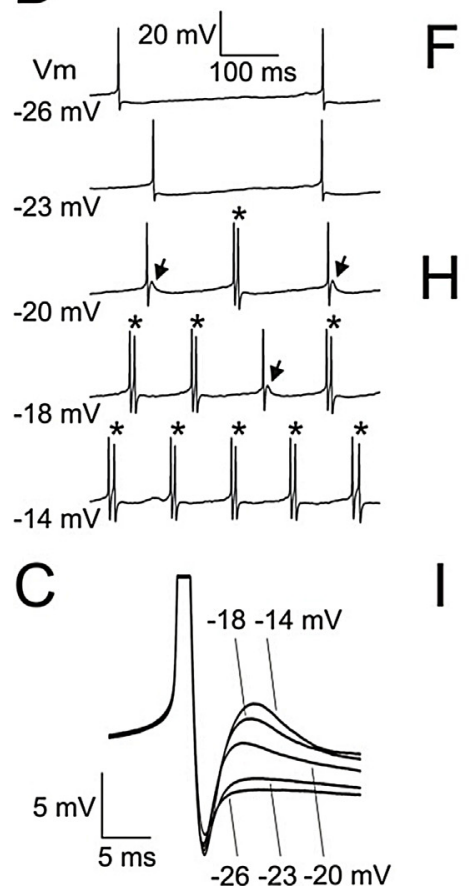

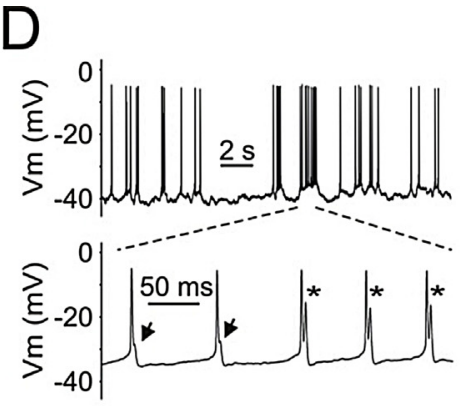
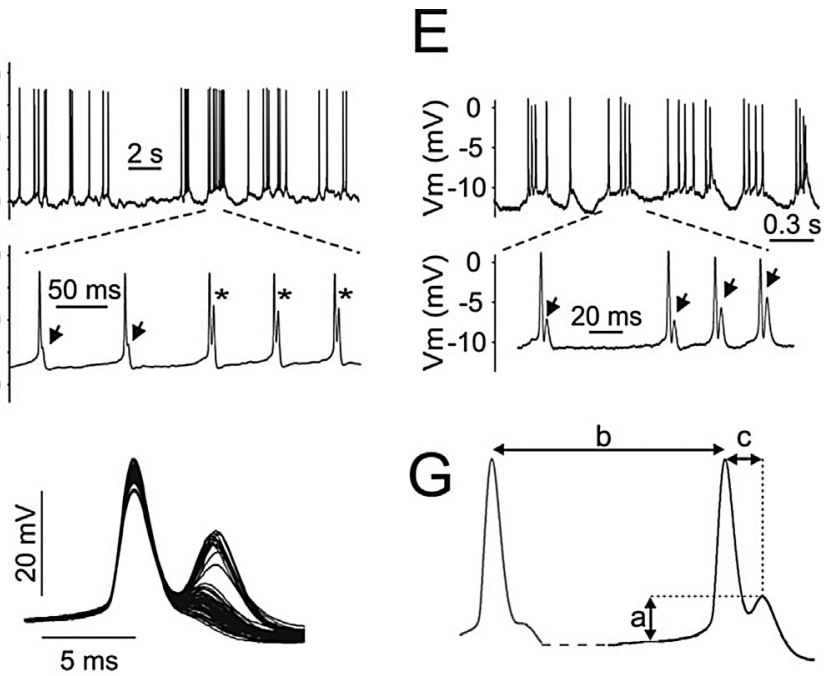

cell 1
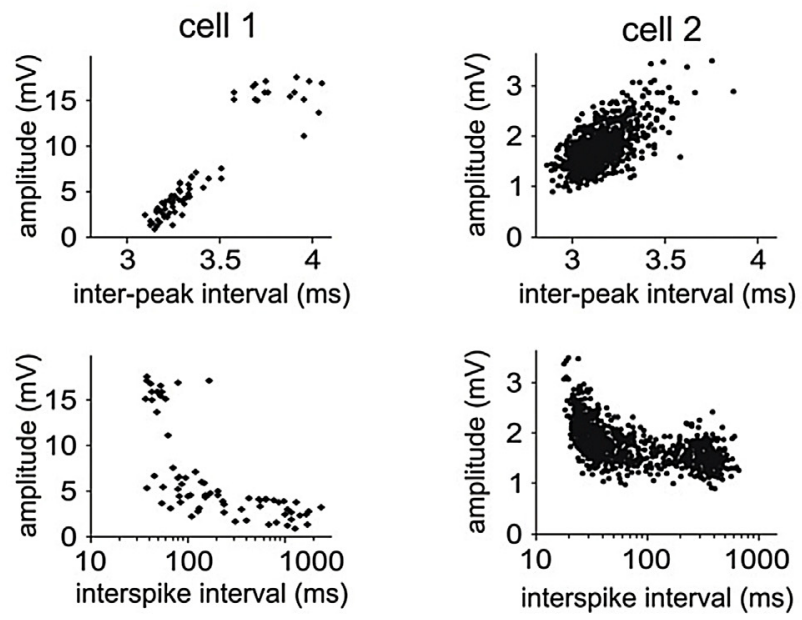

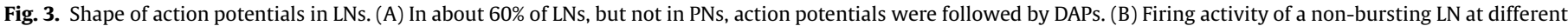

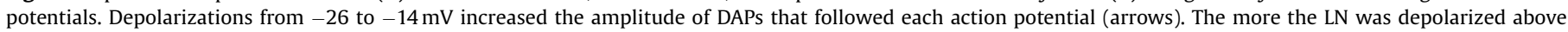

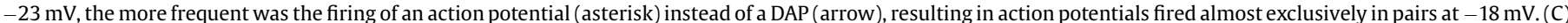

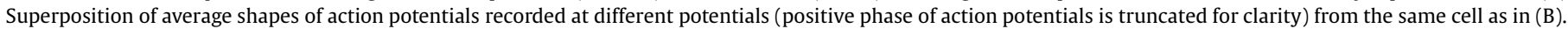

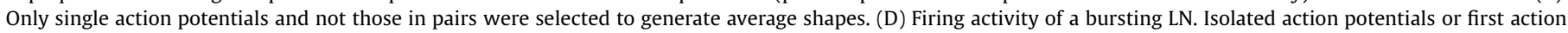

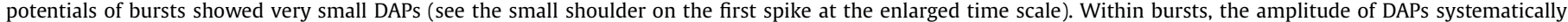

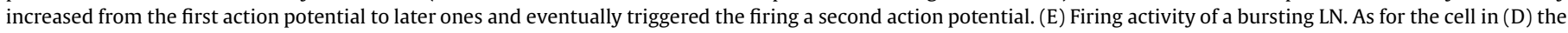

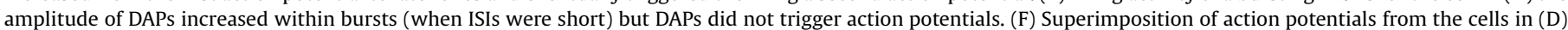

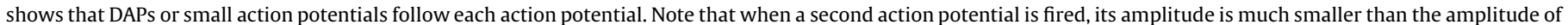

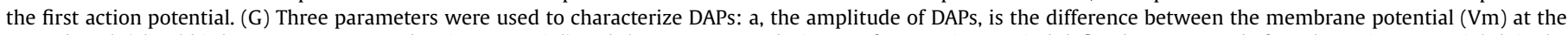

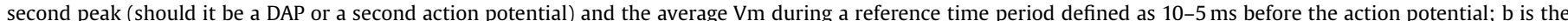

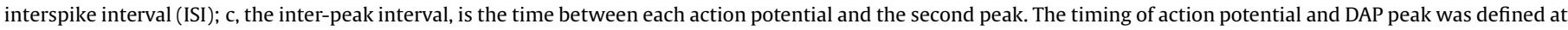

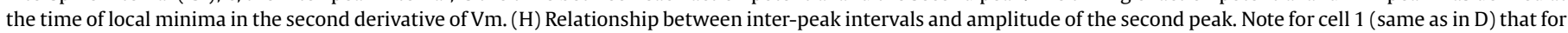

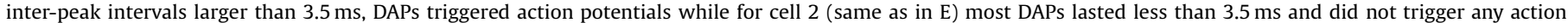

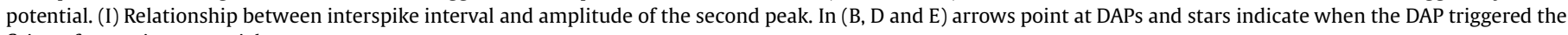
firing of an action potential. 


\subsection{Firing activity of $A L$ neurons}

Action potentials could be readily recorded in the currentclamp mode from most LN cell bodies (85\%) and from ${ }_{\mathrm{LC}} \mathrm{PNs}$ but not from ${ }_{\text {MC }} \mathrm{PNs}$ (Fig. 2A and B). The amplitude of action potentials recorded from LNs $(25.8 \pm 1.0 \mathrm{mV}, \quad N=105)$ and ${ }_{\mathrm{LC}} \mathrm{PNs}$ $(28.6 \pm 3.8 \mathrm{mV}, \quad N=15)$ did not differ significantly $(P=0.37$, $t=0.89, \mathrm{df}=117)$. The spontaneous firing activity of a minority of LNs $(19 \%, 35 / 188)$ included irregular bursts of electrical activity (Fig. 2B). Here we considered bursts as the firing of at least 5 action potentials at a frequency higher than $25 \mathrm{~Hz}$. Other $\mathrm{LNs}$ and all $\mathrm{LC}_{\mathrm{PNs}}$ $(N=15)$ showed more regular electrical activities and did not exhibit bursts. In contrast with ${ }_{\mathrm{LC}} \mathrm{PNs}$, action potentials were recorded only from 3 мCPNs out of 33 and the amplitude of action potentials was strongly reduced $(3.3 \pm 1.9 \mathrm{mV})$ compared to that of LCPNs and LNs (Fig. 2C). To elucidate whether lack of a firing activity from $_{M C} \mathrm{PN}$ cell bodies was due to the brain dissection protocols, we managed to record the activity of three neurons from the MC without having dissected the brain. In those conditions, these three neurons did not exhibit any spiking activity from the cell body. This indicates that action potentials barely propagate up to the cell body of ${ }_{\mathrm{MC}} \mathrm{PNs}$ while they readily propagate in ${ }_{\mathrm{LC}} \mathrm{PNs}$ and LNs. We could, however, record voltage-gated $\mathrm{Na}^{+}$currents from ${ }_{\mathrm{MC}} \mathrm{PNs}$ (Fig. 2D), including ${ }_{\mathrm{MC}} \mathrm{PNs}$ in which action potentials could not be recorded. In 3 LNs from which we did not record action potentials we clearly identified spikelets with an amplitude of 2.0-2.8 mV (Fig. 2E). Spikelets were not $\mathrm{Na}^{+}$-driven since voltage-clamp recordings from these neurons showed no transient inward $\mathrm{Na}^{+}$current (Fig. 2F).

\subsection{Shape of action potentials and firing pattern in LNS}

We then compared the shape of action potentials from LNs and ${ }_{\text {LC }}$ PNs. In $60 \%$ of the LNs (113/188) but not in ${ }_{\text {LC }} \mathrm{PNs}(0 / 15)$, action potentials were followed by short DAPs (Fig. 3). When considering only bursting LNs, the proportion of neurons firing action potentials followed by DAPs was more than 90\% (32/35). DAPs following action potentials were observed both after a long interspike interval (ISI) and within bursts. Depending on the neurons, DAPs appeared at potentials ranging from $-52 \mathrm{mV}$ to $-20 \mathrm{mV}$. The amplitude of DAPs increased with LN depolarization and eventually led to the firing of an additional action potential instead of a DAP resulting in doublets of action potentials (Fig. 3B and $C$ ). For clarity in the following we will refer to the two action potentials in doublets as the first and the second; second peak refers indistinctly to DAPs or second action potentials that are generated within $10 \mathrm{~ms}$ after action potentials. In most neurons, the second action potential of a doublet had a smaller amplitude than the first one (cell 1; Fig. 3D and F) but was clearly distinct from DAPs due to a bimodal distribution of second peak amplitude (Fig. $3 \mathrm{H}$ and I). Finally, in some cells, depolarization up to $+20 \mathrm{mV}$ DAPs did not trigger supplementary action potentials (cell 2; Fig. 3E). Plotting amplitudes of second peaks against the inter-peak interval between first action potentials and second peaks showed that the refractory period that prevents a DAP to trigger an action potential varied between $3.5 \mathrm{~ms}$ (Fig $3 \mathrm{H}$ ) to almost $6 \mathrm{~ms}$ (not shown). When the firing frequency was increased (and thus ISIs reduced) at the beginning of a burst or in response to a depolarizing step, the amplitude of DAPs increased (Fig. 3D and E) and eventually led to the firing of a second action potential. Plotting the amplitude of DAPs vs. ISIs shows that the shorter the ISIs the larger the DAPs (cell 2) or the more frequent a second action potential (cell 1; Fig 3I).

During strong bursts of activity or in response to strong depolarizations eliciting a firing frequency higher than $60-80 \mathrm{~Hz}$, action potential doublets were replaced by a more regular firing activity (Fig. 4). It was then no longer possible to discriminate between first and second action potentials, all action potentials
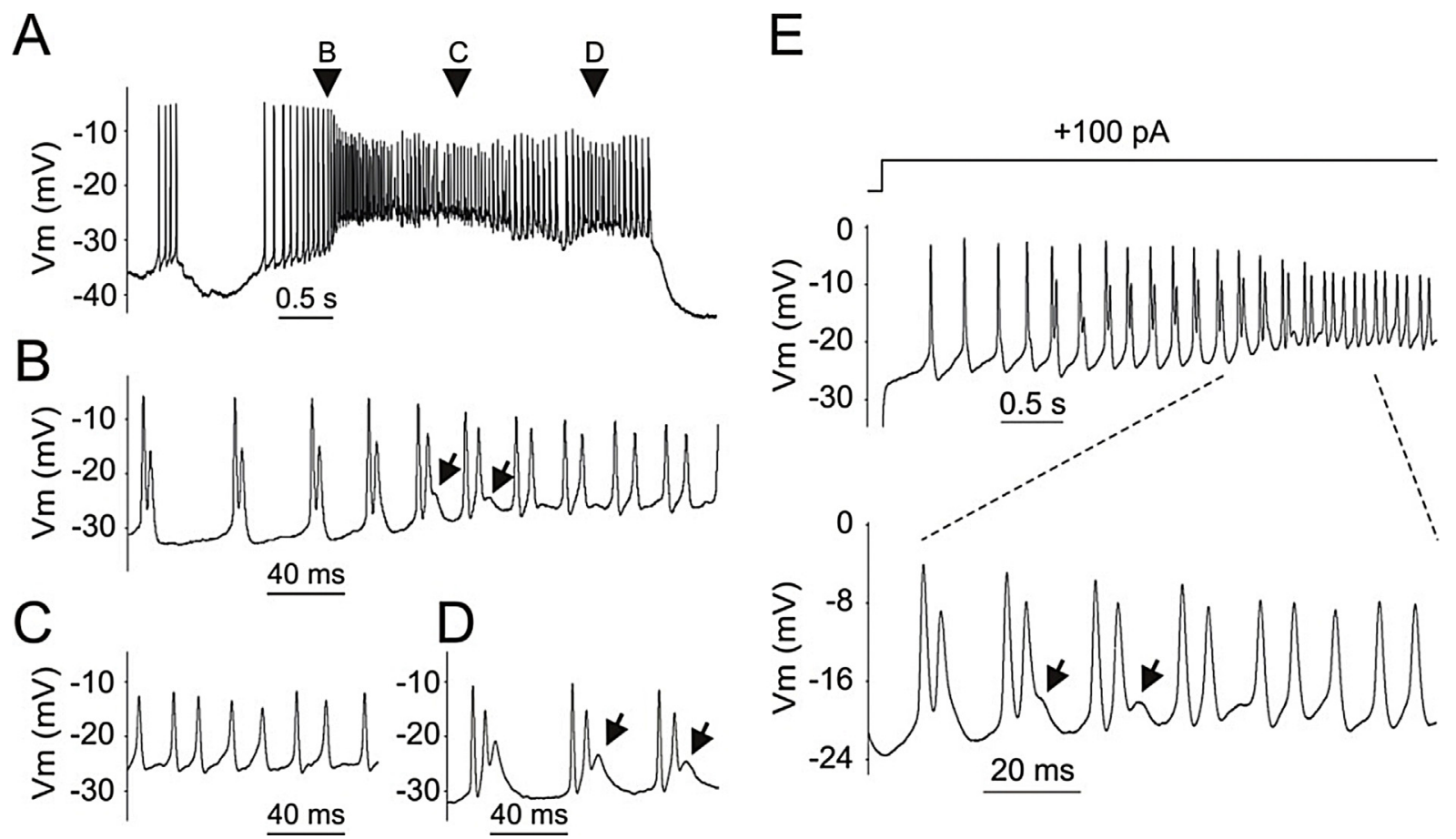

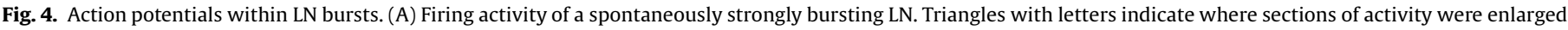

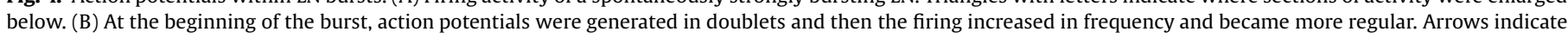

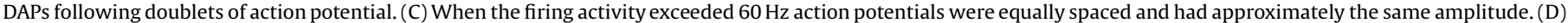

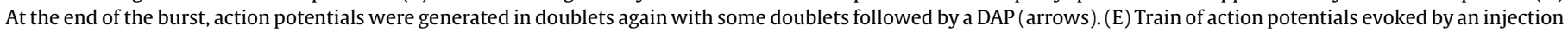
of $100 \mathrm{pA}$. The transition between doublets of action potentials and a high regular activity is enlarged and shows two doublets followed by a DAP (arrows). 
having the same amplitude and ISI (Fig. 4C). In these conditions, action potential doublets followed by a DAP were observed at the transition of the firing regime from an activity in doublets to a high frequency with regular activity and vice versa (Fig. 4B, D and E).

\subsection{Pharmacology of DAP generation}

On other neuron types, DAPs were often found to depend on $\mathrm{Ca}^{2}$ + channels (Bourque, 1986; Jung et al., 2001; Kobayashi et al., 1997; Magee and Carruth, 1999; Metz et al., 2005; Su et al., 2002) or $\mathrm{Ca}^{2}$ +-dependent channels (Fraser and MacVicar, 1996; GhamariLangroudi and Bourque, 2002; Haj-Dahmane and Andrade, 1997; Teruyama and Armstrong, 2007). Therefore, to elucidate the origin of DAPs in moth AL we first verified whether they depend on $\mathrm{Ca}^{2+}$ by quantifying the effects of $\mathrm{Ca}^{2+}$ and other pharmacological agents. In the following, we refer to $6 \mathrm{mM}$ of $\mathrm{Ca}^{2+}$ in the bath solution as the control condition, which might be higher than the physiological concentration. Since not all DAPs triggered an action potential, we measured the average amplitude of second peaks, whether it be a second action potential or a DAP, as shown in Fig. 5A. These measures were done after stepping the membrane potential to approximately $-10 \mathrm{mV}$. The effects of drugs are listed in Fig. 5B, with amplitude of second peaks expressed in percentage of their amplitude in control conditions. The amplitude of second peaks was reversibly reduced when the $\mathrm{Ca}^{2+}$ concentration in the bath was diminished from 6 to $0.5 \mathrm{mM}(49.3 \pm 12.0 \%, N=7$; Fig. $5 \mathrm{~B}$ and C) and to nominally $\mathrm{Ca}^{2+}$-free solution $(18.4 \pm 9.4 \%, N=7$; Fig. 5B and D). Similarly, the bath application of $0.5 \mathrm{mM} \mathrm{Cd}^{2+}$ $(34.1 \pm 13.5 \%, N=11$, Fig. $5 \mathrm{~B}$ and $\mathrm{E})$, a blocker of voltage-gated $\mathrm{Ca}^{2+}$ channels, reversibly inhibited the amplitude of second peaks. Recordings done either in low $\mathrm{Ca}^{2+}$ solutions or after adding $\mathrm{Cd}^{2+}$ demonstrate that DAPs depend on a $\mathrm{Ca}^{2+}$ entry in LNs through voltage-gated $\mathrm{Ca}^{2+}$ channels. Since DAPs in other neuron types were found to depend on $\mathrm{Ca}^{2+}$-activated non-specific (CAN) channels (Fraser and MacVicar, 1996; Ghamari-Langroudi and Bourque, 2002; Teruyama and Armstrong, 2007), we tested the effects of FFA, a blocker of CAN channels (Partridge and Valenzuela, 2000). The application of $200 \mathrm{mM}$ FFA strongly reduced the amplitude of DAPs ( $43.6 \pm 11.1 \% ; N=10$, Fig. 5B and F). The effects of FFA could not be reversed and LNs eventually stopped firing while FFA had no effect on the membrane potential.

Interestingly, blocking DAPs with $\mathrm{Cd}^{2+}$ (Fig. 6A) or after lowering extracellular $\mathrm{Ca}^{2+}$ (not shown) did not prevent spontaneous bursting activity in LNs. Moreover, in addition to the reduction of DAP amplitude, lowering the extracellular $\mathrm{Ca}^{2+}$ concentration from 6 to $0.5 \mathrm{mM}$ or to $0 \mathrm{mM}$ induced an elevation of the spontaneous firing activity. The firing switched to a regime of regular and long lasting bursts for $7 \mathrm{LNs}$ out of 8 in $0 \mathrm{mM} \mathrm{Ca}^{2+}$ and for $1 \mathrm{LN}$ out of 7 in $0.5 \mathrm{mM} \mathrm{Ca}^{2+}$ (Fig. 6B). This explains why the amplitude of action potentials appeared reduced in $0 \mathrm{mM} \mathrm{Ca}{ }^{2+}$ (Fig. 5D). The fast hyperpolarizing afterpotentials (HAPs) that follow each action potential were measured as shown in Fig. 5A and expressed relatively to their amplitude in control saline. The mean firing frequency and duration of action potentials, measured as indicated (Fig. 7D), were also measured and expressed relatively to control conditions. As expected, smaller HAPs after adding $\mathrm{Cd}^{2+}$ or reducing $\mathrm{Ca}^{2+}$ in the bath solution $\left(12 \pm 6 \%\right.$ in $0.5 \mathrm{mM} \mathrm{Cd}^{2+}$; $37 \pm 11 \%$ in $0.5 \mathrm{mM} \mathrm{Ca}^{2+} ; 21 \pm 6 \%$ in $0 \mathrm{mM} \mathrm{Ca}^{2+}$ ) (Fig. $7 \mathrm{~A}$ ) were associated to significant increases in firing frequency $(142 \pm 24 \%$ in $0.5 \mathrm{mM} \mathrm{Cd}^{2+} ; 157 \pm 30 \%$ in $0.5 \mathrm{mM} \mathrm{Ca}^{2+}$ ) (Fig. 7B) and action potential duration $\left(137 \pm 6 \%\right.$ in $0.5 \mathrm{mM} \mathrm{Cd}^{2+} ; 123 \pm 3 \%$ in $0.5 \mathrm{mM}$ $\mathrm{Ca}^{2+} ; 141 \pm 7 \%$ in $0 \mathrm{mM} \mathrm{Ca}^{2+}$ ) (Fig. 7C). It is likely that $\mathrm{Ca}^{2}$ ${ }^{+}$-dependent $\mathrm{K}^{+}$channels are implicated in HAPs and thus are involved in the control of repetitive firing activity. FFA did not attenuate significantly HAPs $(89 \pm 6 \%, N=10)$, it did not modify the duration of action potentials $(100 \pm 2 \%, N=10)$ but it significantly
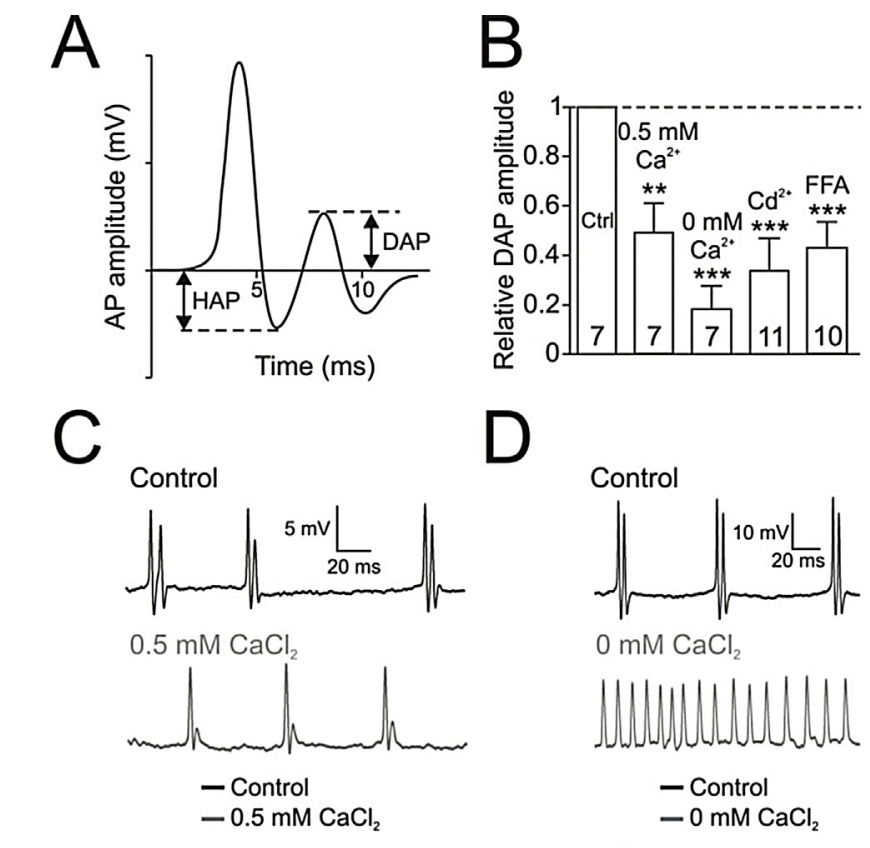

$0 \mathrm{mM} \mathrm{CaCl}_{2}$
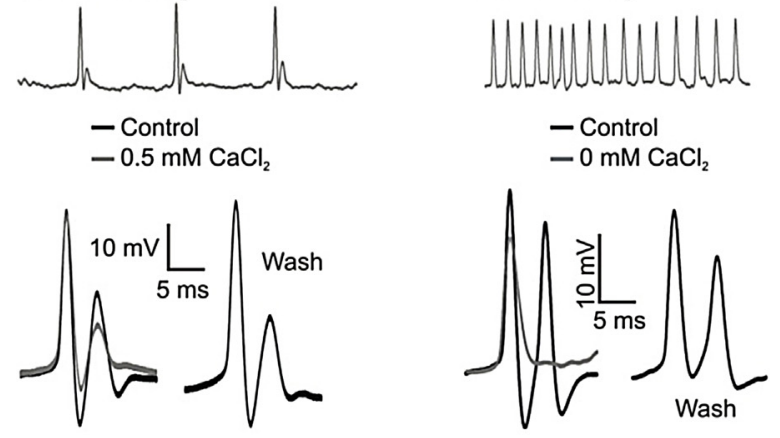

\section{$E$}
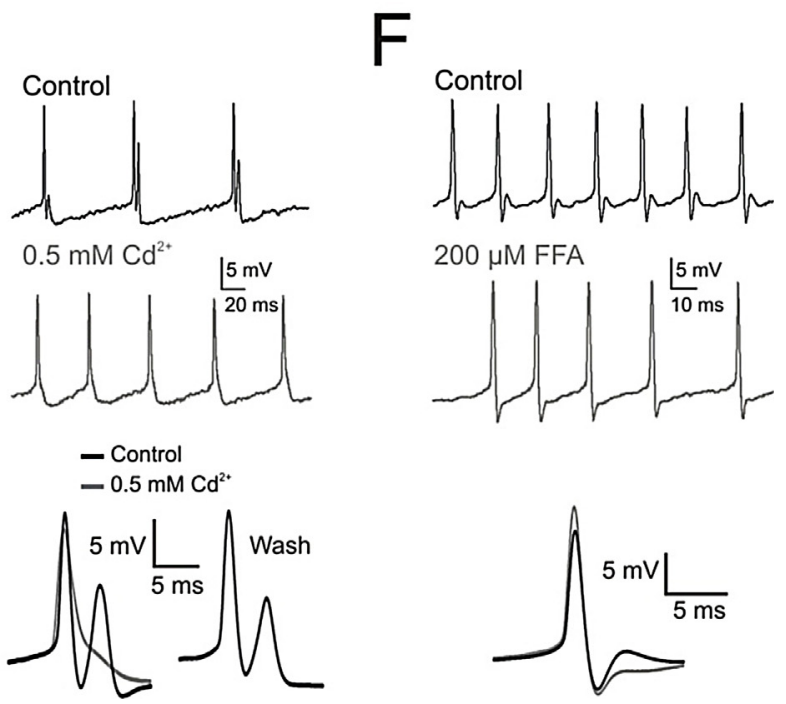

Fig. 5. Pharmacology of DAP and DAP-triggered action potentials in LNs. (A) Parameters used to measure DAPs and hyperpolarizing afterpotentials (HAPs). (B) Comparison of the relative DAP amplitude in response to $0.5 \mathrm{mM} \mathrm{Cd}^{2+}, 200 \mathrm{mM} \mathrm{FFA}$ $0.5 \mathrm{mM} \mathrm{Ca}^{2+}$ and $0 \mathrm{mM} \mathrm{Ca}{ }^{2+}$ as compared to the control saline $\left(\mathrm{Ctrl}, 6 \mathrm{mM} \mathrm{Ca}^{2+}\right.$ ). Means \pm sem; ${ }^{* *}, P<0.01 ;{ }^{* * *}, P<0.001$. Numbers within bars indicate the number of replicates. (C-F) Comparison of control recordings with recordings after perfusing $\mathrm{AL}$ neurons with a solution containing $0.5 \mathrm{mM} \mathrm{Ca}^{2+}(\mathrm{C})$, nominally $0 \mathrm{mM} \mathrm{Ca}^{2+}$ (D), $0.5 \mathrm{mM} \mathrm{Cd}^{2+}$ (E) and $200 \mathrm{mM}$ FFA (F). Average shapes of action potentials are shown under recordings.

reduced the firing activity by almost one half $(53 \pm 8 \%, N=10)$ (Fig. 7A-C). However, no effect of FFA was noticed on the membrane potential.

If the addition of $\mathrm{Cd}^{2+}$ was the most active factor for reducing the amplitude of HAPs, it never elicited any bursting activity $(N=11)$. To understand this observation, we recorded the blockage of $I_{\mathrm{Ca}}$ by $\mathrm{Cd}^{2+}$ in voltage-clamp recordings. All LNs expressed 

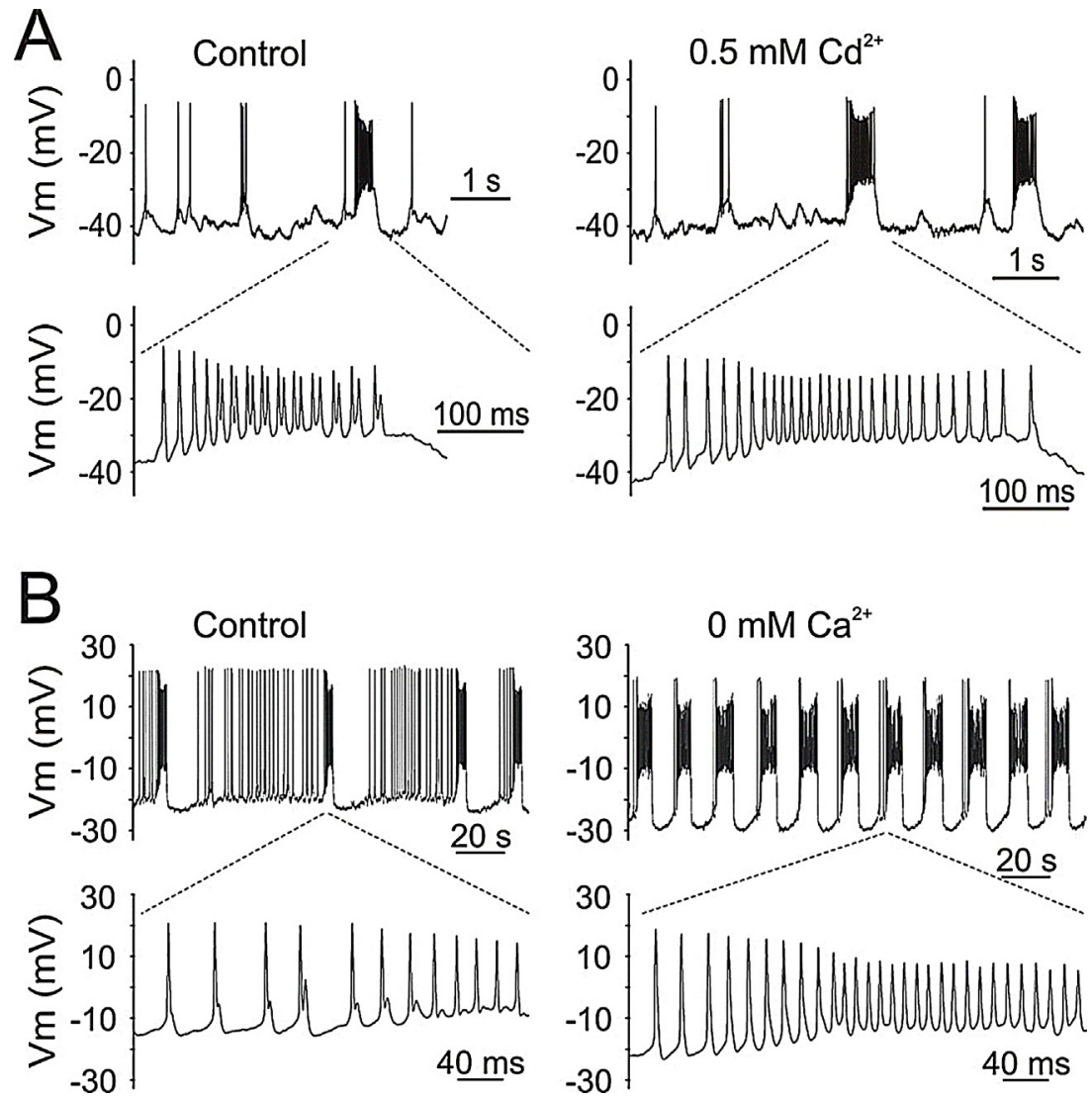

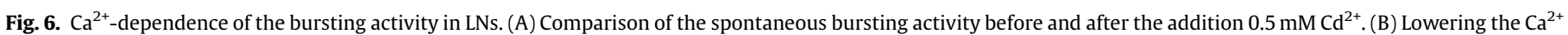
concentration from 6 to $0 \mathrm{mM}$ in the bath solution induced in most LNs a change from a regular or slightly bursting firing activity to a strict bursting regime.

sustained inward currents elicited by depolarizing voltage steps that we identified as $I_{\mathrm{Ca}}$ due to $I-V$ relationships and $\mathrm{Cd}^{2+}$ sensitivity. These currents activated between -40 and $-30 \mathrm{mV}$ and reached a maximum amplitude $(-211 \pm 11 \mathrm{pA}, N=60)$ at $+10 \mathrm{mV}$ (Fig. 7G). The application of $0.5 \mathrm{mM}$ of $\mathrm{Cd}^{2+}$ reversibly inhibited most but not all sustained inward currents (Fig. 7F). A small fraction of the inward current was resistant to $\mathrm{Cd}^{2+}$ in all LNs $(-22 \pm 6 \mathrm{pA}$ at $+10 \mathrm{mV}, N=10)$ while in the same conditions, $100 \%$ of the sustained inward current was blocked in ${ }_{\mathrm{MC}} \mathrm{PNs}(N=9$, not shown). Therefore, the observation that $\mathrm{Cd}^{2+}$ did not elicit any bursting may relate to the fact that part of $I_{\mathrm{Ca}}$ was resistant to the addition of $0.5 \mathrm{mM} \mathrm{Cd}^{2+}$ while $\mathrm{Cd}^{2+}$ is the most effective blocker of $I_{\mathrm{Ca}}$ in Periplaneta americana LNs with an $\mathrm{IC}_{50}$ of $10^{-5} \mathrm{M}$ (Husch et al., 2008).

\subsection{Firing activity of a pheromone-responding $L N$}

If the doublets of action potential induced by DAP have a physiological role in the antennal lobe, they should be observed occasionally from odor-responding neurons. Recordings were done extracellularly, as this is less invasive for the neuron. Indeed, recordings were very stable and the sensitivity of a neuron could be frequently maintained for more than $1 \mathrm{~h}$. Fig. 8 shows the firing activity of a pheromone-sensitive neuron recorded extracellularly in the cumulus of the macroglomerular complex of the AL. This activity shares several features with the activity of the LNs eliciting DAPs and action potential doublets. Doublets were observed during both spontaneous and odor-evoked activity (Fig. 8A), resulting in a bimodal distribution of ISIs (Fig. 8B). The second action potential in the doublets was small but could not originate from another cell recorded simultaneously since it never occurred alone but always followed a large action potential. It could not result from an unusual filtering of the electric signal altering the spike shape, since single spikes were observed in alternation with spike doublets. The frequency of action potentials within doublets $(150-350 \mathrm{~Hz})$ was compatible with a DAP induction. We then plotted the probability of doublet occurrences (ISI $<7 \mathrm{~ms}$ ) as a function of the preceding ISI (Fig. 8C). The probability of doublets was maximal for ISIs typically between 10 and $20 \mathrm{~ms}$ and very low for long ISIs $(>50 \mathrm{~ms})$ indicating that spike doublets mainly lied within bursts. We also observed that the short ISIs $(<5 \mathrm{~ms})$ were never followed by another short ISI revealing the absence of triplets or more action potentials. Other single units recorded extracellularly may have fired doublets, however in most cases the second spike was small and not readily distinguishable from noise or multi-unit activity.

\section{Discussion}

\subsection{Distribution of AL neurons}

The cell bodies of AL neurons are gathered in two main clusters in A. ipsilon, a large lateral cluster (LC) and a smaller medial cluster (MC). The presence of an even smaller antero-ventral cluster that is usually present in moths (Anton and Homberg, 1999; Homberg et al., 1988) may have been overlooked in this work. Mass staining and single neuron staining after patch clamp recordings allowed identifying the distribution of PN and LN cell bodies in these two clusters. The LC gathers LNs and a small proportion of PNs (LCPNs) while the MC seems to be composed only of PN cell bodies (MCPNs). Indeed, we did not find any evidence of the presence of LNs in the MC, similar to what was reported in M. sexta (Hayashi and 

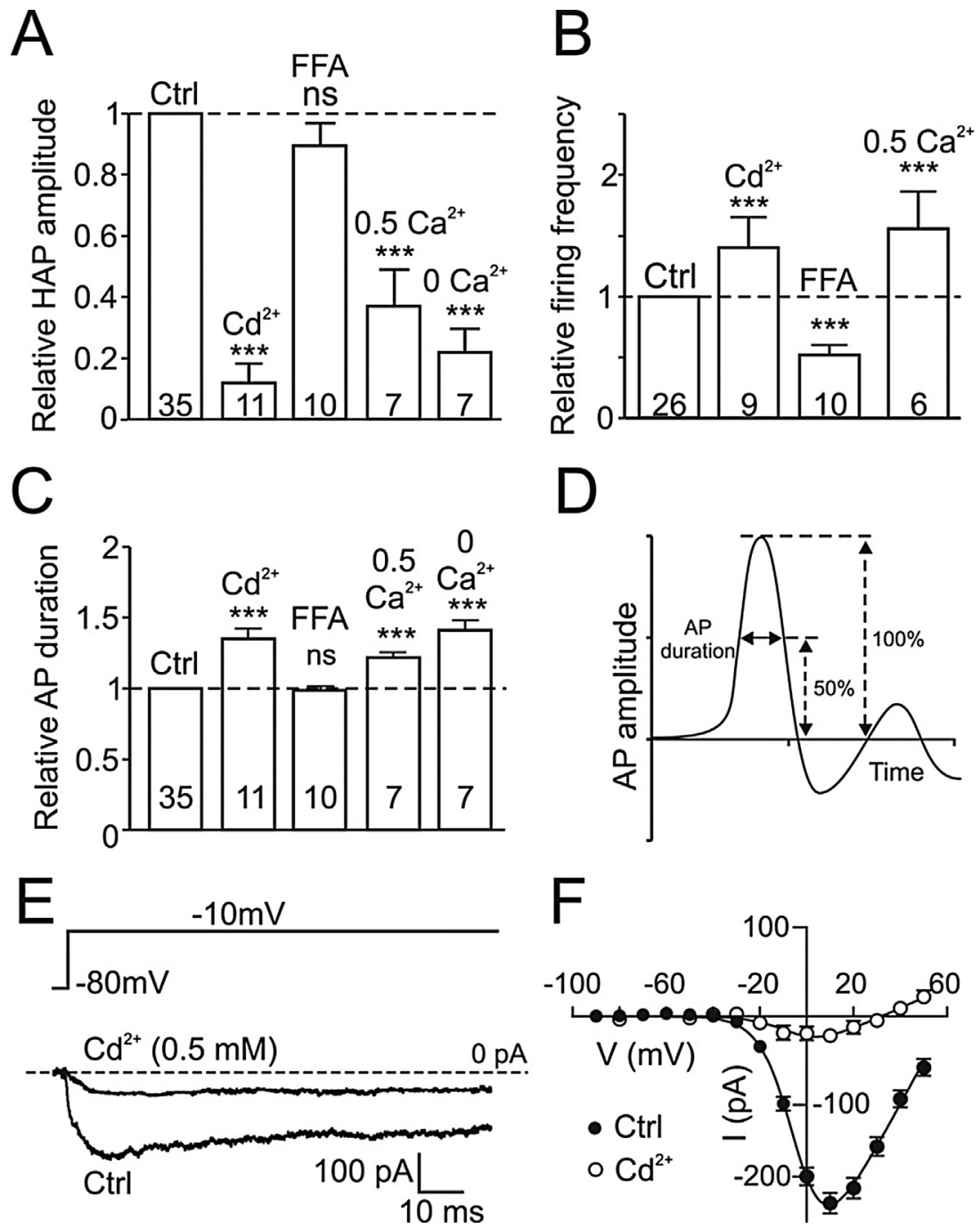

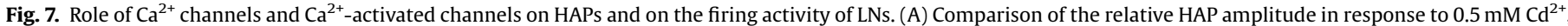

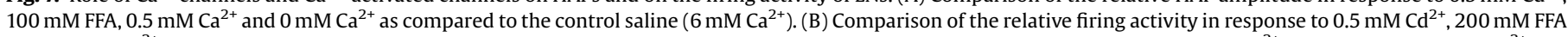

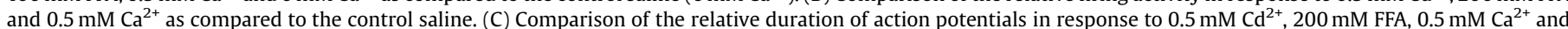

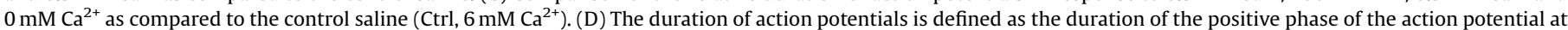

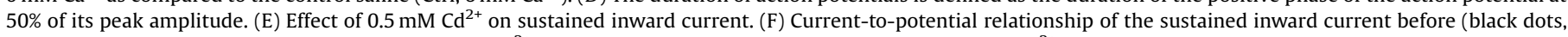

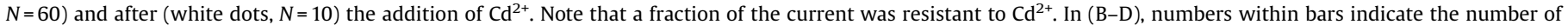
replicates. Mean \pm sem. ${ }^{* * *}, P<0.001$.

Hildebrand, 1990; Homberg et al., 1988). In Bombyx mori ALs, a higher proportion of PNs is also found in the MC than in the LC (Iwano and Kanzaki, 2005; Kanzaki et al., 2003). All stained PNs from the LC showed dense uniglomerular arborizations in the AL and an axon that projects via the mALT to the mushroom bodies and the lateral horn. This morphology corresponds to "PIa" PNs of M. sexta according to the nomenclature of Homberg et al. (1988). PIa PNs have somas in the three clusters in $M$. sexta. PNs from the MC also showed a dense uniglomerular arborization but their projection to higher brain structures could not be studied because visualization and access to their soma for patch-clamp recording required removing the rest of the brain.

\subsection{Firing activity of $A L$ neurons as recorded from the soma}

We then compared the firing activity of LNs and PNs. Action potentials could be readily recorded from PNs and most LNs belonging to the LC. No action potentials could be recorded from a small proportion of LNs. While this might be related to a damaged preparation, small spikelets were recorded from three LNs lacking voltage-dependent $\mathrm{Na}^{+}$channels. This is reminiscent of type II LNs from $P$. americana that lack voltage-dependent $\mathrm{Na}^{+}$channels and therefore do not generate $\mathrm{Na}^{+}$-driven action potentials (Husch et al., 2009a,b). Nonspiking LNs have also been identified in the locust (Laurent and Davidowitz, 1994) but had not been reported in moths. In contrast to ${ }_{\mathrm{LC}} \mathrm{PNs}$, action potentials could rarely be recorded from ${ }_{\mathrm{MC}} \mathrm{PNs}$, indicating that action potentials do not

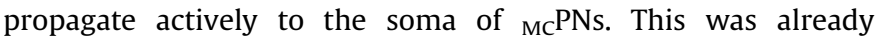
suggested from patch-clamp recordings in Drosophila melanogaster, where small $(<10 \mathrm{mV})$ action potentials were recorded from PN somata (Wilson et al., 2004). The soma is the only location in AL neurons that is accessible to a patch-clamp electrode. Action potential recordings from ${ }_{\mathrm{MC}} \mathrm{PNs}$ in $A$. ipsilon are therefore restricted to intra- or extracellular recordings within the neuropil. The differential action potential propagation to the soma between ${ }_{\mathrm{LC}} \mathrm{PNs}$ and ${ }_{\mathrm{MC}} \mathrm{PNs}$ can result from a larger electrotonic distance of the spike initiation zone to the soma in ${ }_{\mathrm{MC}} \mathrm{PNs}$ than in ${ }_{\mathrm{LC}} \mathrm{PNs}$. Such a difference of electrotonic distance can be due to differences in the anatomy of the primary neurite (length, diameter) and/or location of the spike initiation zone. In Drosophila PNs, action potentials are 
A
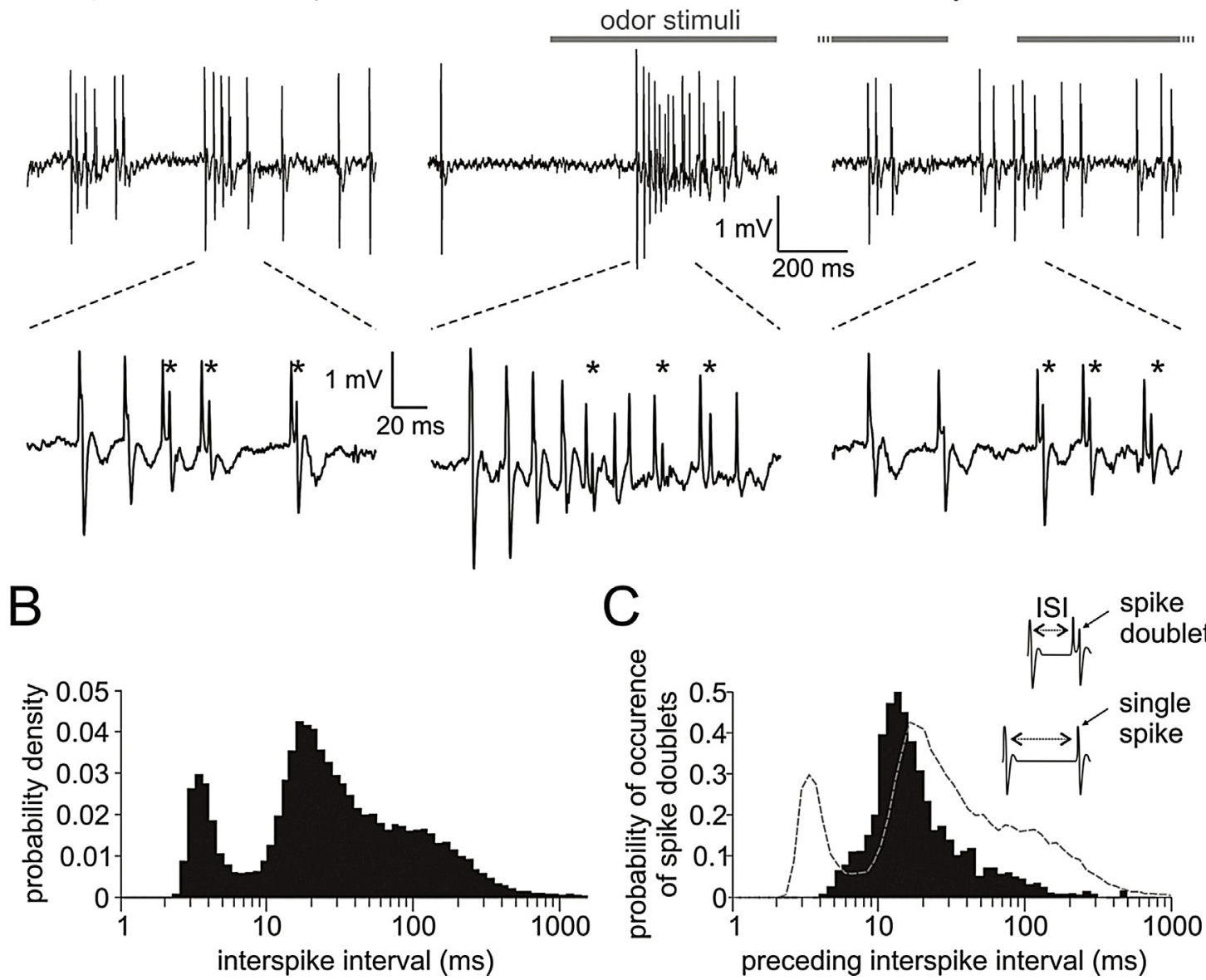

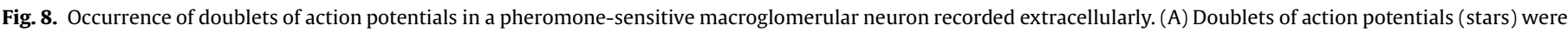

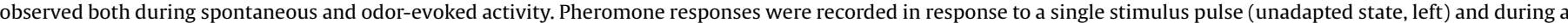

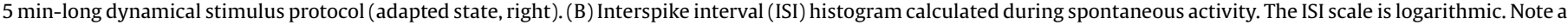

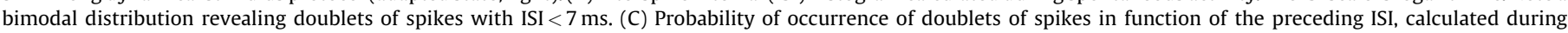

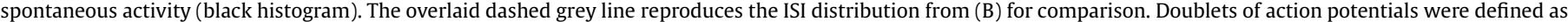
ISI $<7 \mathrm{~ms}$.

thought to be initiated where the primary neurite bifurcates into the axonal and dendritic branches (Gouwens and Wilson, 2009), while in mitral cells of the rat olfactory bulb, action potentials can be initiated in either the soma-axon hillock or in the distal primary dendrite depending on the level of synaptic inputs (Chen et al., 1997). One cannot exclude, however, that voltage-gated channels also contribute to some extent to the active propagation of action potentials in the primary neurite of LNs and ${ }_{\mathrm{LC}} \mathrm{PNs}$ but not of ${ }_{\mathrm{MC}} \mathrm{PNs}$.

In current clamp recordings, the firing of PNs ( ${ }_{\mathrm{LC}} \mathrm{PNs}$ and 3 ${ }_{\mathrm{MC}} \mathrm{PNs}$ ) was regular with action potentials equally spaced and no or faint bursting activities. Some LNs exhibited a clear bursting activity, either with short bursts (less than 10 spikes) or long ones that could last several seconds, similar to plateau potentials described in M. sexta (Mercer et al., 2005). The higher bursting activity in LNs than in PNs is in good agreement with what was reported in Agrotis segetum (Hansson et al., 1994). In the sphinx moth $M$. sexta, the measure of burstiness of AL neurons using a statistical approach (Poisson Surprise) showed contrasting results, PNs produce bursts while LNs fire more regularly, but with an overlapping range of burstiness among PNs and LNs (Lei et al., 2011). These discrepancies may result from the diversity of spiking patterns in moth AL neurons.

\subsection{Mechanism of DAP generation}

In our experimental conditions ( $6 \mathrm{mM}$ of extracellular $\mathrm{Ca}^{2+}$ ), we observed in a majority of LNs, but not in ${ }_{\mathrm{LC}} \mathrm{PNs}$, that action potentials could be followed by brief DAPs $(<10 \mathrm{~ms})$. During steady state current injection DAPs occurred after each action potential and did not require high-frequency firing. When LNs generating action potentials followed by DAP were further depolarized, DAPs could generate a second action potential, the firing being then a succession of spike doublets.

DAPs were described in many neuronal types and rely on specific intrinsic cell mechanisms. They can result from the activation of different channel types including (i) non-inactivating voltage-gated $\mathrm{Na}^{+}$channels (Azouz et al., 1996; Guatteo et al., 1996; Washburn et al., 2000), (ii) $\mathrm{Ca}^{2+}$ channels (Jung et al., 2001; Zhang et al., 1993), (iii) CAN channels (Fraser and MacVicar, 1996; Ghamari-Langroudi and Bourque, 2002) and $\mathrm{Ca}^{2+}$-activated $\mathrm{Cl}^{-}$ channels (Higashi et al., 1993; Martinez-Pinna et al., 2000). The most common mechanism of DAP generation is due to dendritic action potentials. The action potential generated at the soma/axon hillock (referred to as somatic action potential in the following) backpropagates into the dendritic tree, activates voltage-gated channels there, and triggers a slower dendritic action potential that depolarizes the soma and produces a DAP. Recruitment of voltage- 
gated $\mathrm{Ca}^{2+}$ channels in apical dendrites (Magee and Carruth, 1999; Su et al., 2002) or activation of a persistent somatic $\mathrm{Na}^{+}$current (Azouz et al., 1996) by the backpropagating somatic action potential reinforces the somatic DAP. Then, the DAP triggers another action potential, leading to repetitive discharges. This interplay between soma and dendrite named "ping-pong" (Wang, 1999) is an essential part of the burst mechanism in a number of cell types (Coombes and Bressloff, 2005). It has been particularly well characterized in pyramidal cells of the electrosensory lateral line lobe (ELL) of weakly electric fish (Apteronotus leptorhynchus) (Krahe and Gabbiani, 2004; Turner et al., 1994). Since DAPs resulting from action potential backpropagation are short (Magee and Carruth, 1999) and can produce action potential doublets (Lemon and Turner, 2000), we propose that a mechanism of action potential backpropagation from the action potential initiation zone is responsible for the generation of DAPs and doublets in A. ipsilon LNs. Unlike ELL pyramidal cells where DAPs are boosted by a persistent $\mathrm{Na}^{+}$current (Doiron et al., 2003), DAPs rely on $\mathrm{Ca}^{2+}$ conductances in our study, being inhibited in the absence of extracellular $\mathrm{Ca}^{2+}$ or when $\mathrm{Ca}^{2+}$ channel blockers were added to the bath solution. The first action potential recorded after a depolarization, either in response to a current injection or during a burst, did not exhibit a DAP. Therefore, the progressive increase in DAP amplitude after membrane depolarization is likely due to a buildup of $\mathrm{Ca}^{2+}$ when ISIs are short. DAPs may also depend on a CAN channel as they were strongly reduced by FFA, a CAN channel blocker. FFA had no effect on HAPs and on the membrane potential of LNs, but it reduced the firing activity of LNs in a non-reversible manner. Therefore, we cannot exclude that FFA modified other properties of LNs, this compound being known to have other targets (Pézier et al., 2010; White and Aylwin, 1990).

LNs are untypical neurons since they have no axon, the normal output pathway for action potentials in neurons. Moreover, LNs likely can have more than one spike initiation zone as suggested by intracellular recordings showing different action potential sizes (Christensen et al., 1993) or double patch-clamp recordings (Warren et al., 2013). Therefore, action potential backpropagation cannot be from the soma/axon hillock to the dendritic tree but from the spike initiation zone(s) to the apical dendrite.

Several questions arise then, the first one being why are DAPs and spike doublets not present in all LNs and PNs? First, we cannot exclude that due to their small amplitude, DAPs have been overlooked in some LNs. Second, if two populations of LNs differ in their ability to have DAPs, it can either be related to a less efficient spike backpropagation and/or to the absence/lower density of $\mathrm{Ca}^{2+}$ and CAN channels that appear to be essential for both of these events. Spike propagation into the dendrite is usually active and relies on $\mathrm{Na}^{+}$channels (Stuart et al., 1997). A lower dendritic $\mathrm{Na}^{+}-$ channel density in some LNs and in PNs or a higher $\mathrm{K}^{+}$-channel density that could decrease the effectiveness of spike backpropagation (Johnston et al., 1999) may explain why DAPs and spike doublets were not observed in all AL neurons. Differences in dendritic morphology and branching pattern also contribute to the diversity in dendritic spike propagation observed between neurons (Vetter et al., 2001). Indeed, the large diversity of morphology observed within the population of LNs in moths or other insects (Chou et al., 2010; Christensen et al., 1993; Reisenman et al., 2011; Seki and Kanzaki, 2008) may account for differences in dendritic spike propagation.

\subsection{DAPs do not support bursting activity}

DAPs were more often found in bursting (90\%) than in nonbursting LNs (56\%). But interestingly, the pharmacological inhibition of DAPs did not prevent the generation of bursts. Therefore, DAPs could lead to the firing of spike doublets but did not support bursting activity. One can wonder why, since in other systems DAPs, including those dependent on $\mathrm{Ca}^{2+}$ channels, are involved in controlling phasic bursting in neurons (Bourque, 1986; GhamariLangroudi and Bourque, 2002; Haj-Dahmane and Andrade, 1997; Kobayashi et al., 1997; Magee and Carruth, 1999; Metz et al., 2005; Su et al., 2002; Teruyama and Armstrong, 2007; Zhang et al., 1993). In ELL pyramidal cells of weakly electric fish the soma-dendritic ping-pong generates bursts at the soma with an increasing firing frequency during the burst (Krahe and Gabbiani, 2004). The burst terminates with a high-frequency spike doublet, the second spike of the doublet failing to propagate back into the dendrite because it falls within the dendritic refractory period (Lemon and Turner, 2000). This backpropagation failure brings the burst to an end. Similarly, spike doublets were generally not followed by a DAP, suggesting that backpropagation of the second spike of the doublet failed. Indeed, the ISI within a doublet was always shorter than $7 \mathrm{~ms}$ indicating that DAPs fell within (no spike doublet) or close (second spike of the doublet smaller) to the refractory period of the spike generator.

In our recordings, a minority of LNs produced strong bursts of spikes. The firing frequency was decreasing along the burst and not increasing as in ELL pyramidal cells of weakly electric fish. Moreover, bursts could include spike doublets at the beginning that were eventually disappearing when the firing frequency was maximal. Action potential doublets followed by a DAP were only observed at the transition between the two regimes of firing. The inhibition of DAPs or spike doublets using pharmacological blockers did neither prevent bursts nor high frequency firing in response to depolarizing current pulses. These observations suggest that (i) spike doublets and bursts originate from different biophysical mechanisms and that (ii) the change in firing frequency may be relevant only for moderate sensory inputs.

\subsection{Functional significance}

DAPs and spike doublets were recorded from depolarized LNs, either during spontaneous bursts of action potentials or in response to depolarizing currents. One can therefore wonder whether DAPs and spike doublets occur during odorant responses and can thus contribute to the olfactory integration in the AL. To this end we recorded odor-evoked activity of AL neurons from the cumulus of the macroglomerular complex extracellularly. Because the small size of the second spike in doublets often lies under the noise level, we presented a case study with good agreement with patch clamp recordings rather than a population analysis.

What could be the consequences of this mechanism of action potential generation? Spike doublets can potentially amplify the output of LNs to moderate synaptic inputs. It can improve the transfer of information within the AL, as neuronal bursts are transmitted across synapses more reliably than isolated spikes (Lisman, 1997). In this way, spike doublets carry specific information concerning afferent stimuli in ELL pyramidal cells (Chacron et al., 2003; Oswald et al., 2004). Finally, the propagation of action potentials to apical dendrites can provide a retrograde signal informing synapses in the dendritic tree that the neuron has generated an output, being a source of synaptic plasticity. Since the efficacy of backpropagation can vary in different dendrites of the same neuron (Larkum et al., 1996) it offers additional complexity for neuronal computation.

\section{Acknowledgments}

We thank Jan Kropf and Wolfgang Roessler (University of Wuerzburg, Germany) for their help in retrograde labeling. This work was funded by the state program Investissements d'avenir managed by ANR (grant ANR-10-BINF-05 "Pherotaxis"). 


\section{References}

Anton, S., Homberg, U., 1999. Antennal lobe structure. In: Hansson, B.S. (Ed.), Insect Olfaction. Springer, Berlin, pp. 97-124.

Azouz, R., Jensen, M.S., Yaari, Y., 1996. Ionic basis of spike after-depolarization and burst generation in adult rat hippocampal CA1 pyramidal cells. J. Physiol. 492, $211-223$.

Barrozo, R.B., Jarriault, D., Deisig, N., Gemeno, C., Monsempes, C., Lucas, P., Gadenne, C., Anton, S., 2011. Mating-induced differential coding of plant odour and sex pheromone in a male moth. Eur. J. Neurosci. 33, 1841-1850.

Belmabrouk, H., Nowotny, T., Rospars, J.-P., Martinez, D., 2011. Interaction of cellular and network mechanisms for efficient pheromone coding in moths. Proc. Natl Acad. Sci. U. S. A. 108, 19790-19795.

Bicker, G., 1999. Histochemistry of classical neurotransmitters in antennal lobes and mushroom bodies of the honeybee. Microsc. Res. Tech. 45, 174-183.

Bourque, C.W., 1986. Calcium-dependent spike after-current induces burst firing in magnocellular neurosecretory cells. Neurosci. Lett. 70, 204-209.

Carlsson, M.A., Diesner, M., Schachtner, J., Nassel, D.R., 2010. Multiple neuropeptides in the Drosophila antennal lobe suggest complex modulatory circuits. J. Comp. Neurol. 518, 3359-3380.

Chacron, M.J., Doiron, B., Maler, L., Longtin, A., Bastian, J., 2003. Non-classical receptive field mediates switch in a sensory neuron's frequency tuning. Nature 423, 77-81.

Chaffiol, A., Kropf, J., Barrozo, R.B., Gadenne, C., Rospars, J.P., Anton, S., 2012. Plant odour stimuli reshape pheromonal representation in neurons of the antennal lobe macroglomerular complex of a male moth. J. Exp. Biol. 215, 1670-1680.

Chen, W.R., Midtgaard, J., Shepherd, G.M., 1997. Forward and backward propagation of dendritic impulses and their synaptic control in mitral cells. Science 278, 463-467.

Chou, Y.H., Spletter, M.L., Yaksi, E., Leong, J.C., Wilson, R.I., Luo, L., 2010. Diversity and wiring variability of olfactory local interneurons in the Drosophila antennal lobe. Nat. Neurosci. 13, 439-449.

Christensen, T.A., Waldrop, B.R., Harrow, I.D., Hildebrand, J.G., 1993. Local interneurons and information processing in the olfactory glomeruli of the moth Manduca sexta. J. Comp. Physiol. 173, 385-399.

Coombes, S., Bressloff, P.C., 2005. Bursting. The Genesis of Rhythm in the Nervous System. Word Scientific Publishing Co., Hackensack, NJ, USA, London, UK.

Deisig, N., Kropf, J., Vitecek, S., Pevergne, D., Rouyar, A., Sandoz, J.C., Lucas, P., Gadenne, C., Anton, S., Barrozo, R., 2012. Differential interactions of sex pheromone and plant odour in the olfactory pathway of a male moth. PLoS One 7, e33159.

Doiron, B., Noonan, L., Lemon, N., Turner, R.W., 2003. Persistent $\mathrm{Na}^{+}$current modifies burst discharge by regulating conditional backpropagation of dendritic spikes. J. Neurophysiol. 89, 324-337.

Fonta, C., Sun, X.-J., Masson, C., 1993. Morphology and spatial distribution of bee antennal lobe interneurones responsive to odours. Chem. Senses 18, 101-119.

Fraser, D.D., MacVicar, B.A., 1996. Cholinergic-dependent plateau potential in hippocampal CA1 pyramidal neurons. J. Neurosci. 16, 4113-4128.

Fusca, D., Husch, A., Baumann, A., Kloppenburg, P., 2013. Choline acetyltransferaselike immunoreactivity in a physiologically distinct subtype of olfactory nonspiking local interneurons in the cockroach (Periplaneta americana). J. Comp. Neurol. 521, 3556-3569.

Ghamari-Langroudi, M., Bourque, C.W., 2002. Flufenamic acid blocks depolarizing afterpotentials and phasic firing in rat supraoptic neurones. J. Physiol. 545, $537-$ 542.

Gouwens, N.W., Wilson, R.I., 2009. Signal propagation in Drosophila central neurons. J. Neurosci. 29, 6239-6249.

Gremiaux, A., Nowotny, T., Martinez, D., Lucas, P., Rospars, J.-P., 2012. Modelling the signal delivered by a population of first-order neurons in a moth olfactory system. Brain Res. 1434, 123-135.

Guatteo, E., Franceschetti, S., Bacci, A., Avanzini, G., Wanke, E., 1996. A TTX-sensitive conductance underlying burst firing in isolated pyramidal neurons from rat neocortex. Brain Res. 741, 1-12.

Haj-Dahmane, S., Andrade, R., 1997. Calcium-activated cation nonselective current contributes to the fast afterdepolarization in rat prefrontal cortex neurons. J. Neurophysiol. 78, 1983-1989.

Hansson, B.S., Anton, S., 2000. Function and morphology of the antennal lobe: new developments. Annu. Rev. Entomol. 45, 203-231.

Hansson, B.S., Anton, S., Christensen, T.A., 1994. Structure and function of antennal lobe neurons in the male turnip moth, Agrotis segetum (Lepidoptera: Noctuidae). J. Comp. Physiol. 175 547-562.

Hayashi, J.H., Hildebrand, J.G., 1990. Insect olfactory neurons in vitro: morphological and physiological characterization of cells from the developing antennal lobes of Manduca sexta. J. Neurosci. 10, 848-859.

Higashi, H., Tanaka, E., Inokuchi, H., Nishi, S., 1993. Ionic mechanisms underlying the depolarizing and hyperpolarizing afterpotentials of single spike in guinea-pig cingulate cortical neurons. Neuroscience 55, 129-138.

Homberg, U., Hoskins, S.G., Hildebrand, J.G., 1995. Distribution of acetylcholinesterase activity in the deutocerebrum of the sphinx moth Manduca sexta. Cell Tissue Res. 279, 249-259.

Homberg, U., Montague, R.A., Hilddebrand, J.G., 1988. Anatomy of antenno-cerebral pathways in the brain of the sphinx moth Manduca sexta. Cell Tissue Res. 254, 255-281.
Homberg, U., Müller, U., 1999. Neuroactive substances in the antennal lobe. In: Hansson, B.S. (Ed.), Insect Olfaction. Springer, Berlin, Heidelberg, New York, pp. 181-206.

Huang, J., Zhang, W., Qiao, W., Hu, A., Wang, Z., 2010. Functional connectivity and selective odor responses of excitatory local interneurons in Drosophila antennal lobe. Neuron 67, 1021-1033.

Husch, A., Hess, S., Kloppenburg, P., 2008. Functional parameters of voltageactivated $\mathrm{Ca}^{2+}$ currents from olfactory interneurons in the antennal lobe of Periplaneta americana. J. Neurophysiol. 99, 320-332.

Husch, A., Paehler, M., Fusca, D., Paeger, L., Kloppenburg, P., 2009a. Calcium current diversity in physiologically different local interneuron types of the antennal lobe. J. Neurosci. 29, 716-726.

Husch, A., Paehler, M., Fusca, D., Paeger, L., Kloppenburg, P., 2009b. Distinct electrophysiological properties in subtypes of nonspiking olfactory local interneurons correlate with their cell type-specific $\mathrm{Ca}^{2+}$ current profiles. J. Neurophysiol. 102, 2834-2845.

Ignell, R., Root, C.M., Birse, R.T., Wang, J.W., Nassel, D.R., Winther, A.M., 2009. Presynaptic peptidergic modulation of olfactory receptor neurons in Drosophila. Proc. Natl. Acad. Sci. U. S. A. 106, 13070-13075.

Iwano, M., Kanzaki, R., 2005. Immunocytochemical identification of neuroactive substances in the antennal lobe of the male silkworm moth Bombyx mori. Zool. Sci. 22, 199-211.

Jarriault, D., Gadenne, C., Lucas, P., Rospars, J.-P., Anton, S., 2010. Transformation of the sex pheromone signal in the Noctuid moth Agrotis ipsilon: from peripheral input to antennal lobe output. Chem. Senses 35, 705-715.

Johnston, D., Hoffman, D.A., Colbert, C.M., Magee, J.C., 1999. Regulation of backpropagating action potentials in hippocampal neurons. Curr. Opin. Neurobiol. 9, 288-292.

Jung, H.Y., Staff, N.P., Spruston, N., 2001. Action potential bursting in subicular pyramidal neurons is driven by a calcium tail current. J. Neurosci. 21, 3312-3321.

Kanzaki, R., Soo, K., Seki, Y., Wada, S., 2003. Projections to higher olfactory centers from subdivisions of the antennal lobe macroglomerular complex of the male silkmoth. Chem. Senses 28, 113-130.

Kloppenburg, P., Ferns, D., Mercer, A.R., 1999. Serotonin enhances central olfactory neuron responses to female sex pheromone in the male sphinx moth Manduca sexta. J. Neurosci. 19, 8172-8181.

Kobayashi, M., Inoue, T., Matsuo, R., Masuda, Y., Hidaka, O., Kang, Y., Morimoto, T., 1997. Role of calcium conductances on spike afterpotentials in rat trigeminal motoneurons. J. Neurophysiol. 77, 3273-3283.

Krahe, R., Gabbiani, F., 2004. Bursting activity in weakly electric fish. In: Feng, J. (Ed.), Computational Neuroscience, A Comprehensive Approach. Chapman \& Hall/ CRC, pp. 215-252.

Larkum, M.E., Rioult, M.G., Luscher, H.R., 1996. Propagation of action potentials in the dendrites of neurons from rat spinal cord slice cultures. J. Neurophysiol. 75, 154-170.

Laurent, G., Davidowitz, H., 1994. Encoding of olfactory information with oscillating neural assemblies. Science 265, 1872-1875.

Lei, H., Reisenman, C.E., Wilson, C.H., Gabbur, P., Hildebrand, J.G., 2011. Spiking patterns and their functional implications in the antennal lobe of the tobacco hornworm Manduca sexta. PLoS One 6, e23382.

Lemon, N., Turner, R.W., 2000. Conditional spike backpropagation generates burst discharge in a sensory neuron. J. Neurophysiol. 84, 1519-1530.

Lisman, J.E., 1997. Bursts as a unit of neural information: making unreliable synapses reliable. Trends Neurosci. 20, 38-43.

Magee, J.C., Carruth, M., 1999. Dendritic voltage-gated ion channels regulate the action potential firing mode of hippocampal CA1 pyramidal neurons. J. Neurophysiol. 82, 1895-1901.

Martinez-Pinna, J., McLachlan, E.M., Gallego, R., 2000. Distinct mechanisms for activation of $\mathrm{Cl}^{-}$and $\mathrm{K}^{+}$currents by $\mathrm{Ca}^{2+}$ from different sources in mouse sympathetic neurones. J. Physiol. 527 (Pt. 2), 249-264.

Martinez, D., Chaffiol, A., Voges, N., Gu, Y., Anton, S., Rospars, J.P., Lucas, P., 2013. Multiphasic on/off pheromone signalling in moths as neural correlates of a search strategy. PLoS One 8, e61220.

Mercer, A.R., Hayashi, J.H., Hildebrand, J.G., 1995. Modulatory effects of 5hydroxytryptamine on voltage-activated currents in cultured antennal lobe neurones of the sphinx moth Manduca sexta. J. Exp. Biol. 198, 613-627.

Mercer, A.R., Hildebrand, J.G., 2002. Developmental changes in the density of ionic currents in antennal-lobe neurons of the sphinx moth, Manduca sexta. J. Neurophysiol. 87, 2664-2675.

Mercer, A.R., Kloppenburg, P., Hildebrand, J.G., 1996. Serotonin-induced changes in the excitability of cultured antennal-lobe neurons of the sphinx moth Manduca sexta. J. Comp. Physiol. 178, 21-31.

Mercer, A.R., Kloppenburg, P., Hildebrand, J.G., 2005. Plateau potentials in developing antennal-lobe neurons of the moth, Manduca sexta. J. Neurophysiol. 93, 1949-1958.

Metz, A.E., Jarsky, T., Martina, M., Spruston, N., 2005. R-type calcium channels contribute to afterdepolarization and bursting in hippocampal CA1 pyramidal neurons. J. Neurosci. 25, 5763-5773.

Olsen, S.R., Bhandawat, V., Wilson, R.I., 2007. Excitatory interactions between olfactory processing channels in the Drosophila antennal lobe. Neuron 54, 89 103.

Olsen, S.R., Wilson, R.I., 2008. Lateral presynaptic inhibition mediates gain control in an olfactory circuit. Nature 452, 956-960.

Oswald, A.M., Chacron, M.J., Doiron, B., Bastian, J., Maler, L., 2004. Parallel processing of sensory input by bursts and isolated spikes. J. Neurosci. 24, 4351-4362. 
Partridge, L.D., Valenzuela, C.F., 2000. Block of hippocampal CAN channels by flufenamate. Brain Res. 867, 143-148.

Pézier, A., Grauso, M., Acquistapace, A., Monsempes, C., Rospars, J.-P., Lucas, P., 2010. Calcium activates a chloride conductance likely involved in olfactory receptor neuron repolarisation in the moth Spodoptera littoralis. J. Neurosci. 30, 63236333.

Poitout, S., Buès, R., 1974. Elevage de chenilles de vingt-huit espèces de Lépidoptères Noctuidae et de deux espèces d'Arctiidae sur milieu artificiel simple. Particularités de l'élevage selon les espèces. Ann. Zool. Ecol. Anim. 6, 431-441.

Reisenman, C.E., Dacks, A.M., Hildebrand, J.G., 2011. Local interneuron diversity in the primary olfactory center of the moth Manduca sexta. J. Comp. Physiol. 197, 653-665.

Root, C.M., Masuyama, K., Green, D.S., Enell, L.E., Nassel, D.R., Lee, C.H., Wang, J.W., 2008. A presynaptic gain control mechanism fine-tunes olfactory behavior. Neuron 59, 311-321.

Rospars, J.-P., 1988. Structure and development of the insect antennodeutocerebral system. Int. J. Insect Morphol. Embryol. 17, 243-294.

Rospars, J.P., Gremiaux, A., Jarriault, D., Chaffiol, A., Monsempes, C., Deisig, N., Anton, S., Lucas, P., Martinez, D., 2014. Heterogeneity and convergence of olfactory firstorder neurons account for the high speed and sensitivity of second-order neurons. PLoS Comput. Biol. 10, e1003975.

Schafer, S., Bicker, G., 1986. Distribution of GABA-like immunoreactivity in the brain of the honeybee. J. Comp. Neurol. 246, 287-300.

Seki, Y., Kanzaki, R., 2008. Comprehensive morphological identification and GABA immunocytochemistry of antennal lobe local interneurons in Bombyx mori. J. Comp. Neurol. 506, 93-107.

Seki, Y., Rybak, J., Wicher, D., Sachse, S., Hansson, S., 2010. Physiological and morphological characterization of local interneurons in the Drosophila antennal lobe. J. Neurophysiol. 104, 1007-1019.

Shang, Y., Claridge-Chang, A., Sjulson, L., Pypaert, M., Miesenbock, G., 2007. Excitatory local circuits and their implications for olfactory processing in the fly antennal lobe. Cell 128, 601-612.

Stuart, G., Spruston, N., Sakmann, B., Hausser, M., 1997. Action potential initiation and backpropagation in neurons of the mammalian CNS. Trends Neurosci. 20, 125-131.

Su, H., Sochivko, D., Becker, A., Chen, J., Jiang, Y., Yaari, Y., Beck, H., 2002. Upregulation of a T-type $\mathrm{Ca}^{2+}$ channel causes a long-lasting modification of neuronal firing mode after status epilepticus. J. Neurosci. 22, 3645-3655.
Teruyama, R., Armstrong, W.E., 2007. Calcium-dependent fast depolarizing afterpotentials in vasopressin neurons in the rat supraoptic nucleus. J. Neurophysiol. 98, 2612-2621.

Turner, R.W., Maler, L., Deerinck, T., Levinson, S.R., Ellisman, M.H., 1994. TTX sensitive dendritic sodium channels underlie oscillatory discharge in a vertebrate sensory neuron. J. Neurosci. 14, 6453-6471.

Vetter, P., Roth, A., Hausser, M., 2001. Propagation of action potentials in dendrites depends on dendritic morphology. J Neurophysiol. 85, 926-937.

Vosshall, L.B., Wong, A.M., Axel, R., 2000. An olfactory sensory map in the fly brain. Cell 102, 147-159.

Wang, X.J., 1999. Fast burst firing and short-term synaptic plasticity: a model of neocortical chattering neurons. Neuroscience 89, 347-362.

Warren, B., Fusca, D., Kloppenburg, P., 2013. Chemical intercellular signaling in the antennal lobe of the cockroach Periplaneta americana. 13th European Symposium on Insect Olfaction and Taste, Villasimius, Cagliari, Italy.

Warren, B., Kloppenburg, P., 2014. Rapid and slow chemical synaptic interactions of cholinergic projection neurons and GABAergic local interneurons in the insect antennal lobe. J. Neurosci. 34, 13039-13046.

Washburn, D.L., Anderson, J.W., Ferguson, A.V., 2000. A subthreshold persistent sodium current mediates bursting in rat subfornical organ neurones. J. Physiol. 529, 359-371.

White, M.M., Aylwin, M., 1990. Niflumic and flufenamic acids are potent reversible blockers of $\mathrm{Ca}^{2+}$-activated Cl- channels in Xenopus oocytes. Mol. Pharmacol. 37, $720-724$.

Wilson, R.I., 2013. Early olfactory processing in Drosophila: mechanisms and principles. Annu. Rev. Neurosci. 36, 217-241.

Wilson, R.I., Laurent, G., 2005. Role of GABAergic inhibition in shaping odor-evoked spatiotemporal patterns in the Drosophila antennal lobe. J. Neurosci. 25, 90699079.

Wilson, R.I., Turner, G.C., Laurent, G., 2004. Transformation of olfactory representations in the Drosophila antennal lobe. Science 303, 366-370.

Yaksi, E., Wilson, R.I., 2010. Electrical coupling between olfactory glomeruli. Neuron 67, 1034-1047.

Zhang, L., Valiante, T.A., Carlen, P.L., 1993. Contribution of the low-threshold T-type calcium current in generating the post-spike depolarizing afterpotential in dentate granule neurons of immature rats. J Neurophysiol. 70, 223-231. 